\title{
Camel regulates development of the brain ventricular system
}

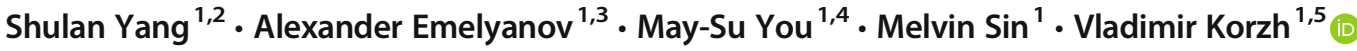

Received: 8 April 2020 / Accepted: 29 July 2020 / Published online: 9 September 2020

(C) The Author(s) 2020

\begin{abstract}
Development of the brain ventricular system of vertebrates and the molecular mechanisms involved are not fully understood. The developmental genes expressed in the elements of the brain ventricular system such as the ependyma and circumventricular organs act as molecular determinants of cell adhesion critical for the formation of brain ventricular system. They control brain development and function, including the flow of cerebrospinal fluid. Here, we describe the novel distantly related member of the zebrafish L1-CAM family of genes-camel. Whereas its maternal transcripts distributed uniformly, the zygotic transcripts demonstrate clearly defined expression patterns, in particular in the axial structures: floor plate, hypochord, and roof plate. camel expresses in several other cell lineages with access to the brain ventricular system, including the midbrain roof plate, subcommissural organ, organum vasculosum lamina terminalis, median eminence, paraventricular organ, flexural organ, and inter-rhombomeric boundaries. This expression pattern suggests a role of Camel in neural development. Several isoforms of Camel generated by differential splicing of exons encoding the sixth fibronectin type III domain enhance cell adhesion differentially. The antisense oligomer morpholino-mediated loss-of-function of Camel affects cell adhesion and causes hydrocephalus and scoliosis manifested via the tail curled down phenotype. The subcommissural organ's derivative - the Reissner fiberparticipates in the flow of cerebrospinal fluid. The Reissner fiber fails to form upon morpholino-mediated Camel loss-of-function. The Camel mRNA-mediated gain-of-function causes the Reissner fiber misdirection. This study revealed a link between Chlla/ Camel and Reissner fiber formation, and this supports the idea that CHL1 is one of the scoliosis factors.
\end{abstract}

Keywords Subcommissural organ $\cdot$ Flexural organ $\cdot$ Floor plate $\cdot$ Roof plate $\cdot$ Hypochord $\cdot$ Ependyma

\section{Introduction}

The subcommissural organ (SCO) is an ependymal brain gland found in the diencephalic roof of the third ventricle at the entrance to the cerebral aqueduct. It synthesizes and

Electronic supplementary material The online version of this article (https://doi.org/10.1007/s00441-020-03270-1) contains supplementary material, which is available to authorized users.

Vladimir Korzh

vkorzh@iimcb.gov.pl

1 Institute of Molecular and Cell Biology, Agency for Science, Technology and Research, Singapore, Singapore

2 Translational Medicine Centre, The First Affiliated Hospital, Sun Yat-sen University, Guangzhou, China

3 Institute for Research on Cancer and Aging, Nice, France

4 National Health Research Institutes, Zhunan, Taiwan

5 International Institute of Molecular and Cell Biology, Warsaw, Poland releases into the third ventricle (vIII) large glycoproteins that polymerize and form the Reissner fiber (RF), a filamentous structure spanning the brain ventricular system (BVS) starting from the vIII and extending through the central canal to the posterior end of the spinal cord. The RF forms by a combination of secreted proteins released to the cerebrospinal fluid (CSF) by the SCO (Nicholls 1913; Sterba 1969; Rodríguez et al. 1992, 1998; Muñoz et al. 2019). Several genes or regulators of axial midline structures including, but not limited to, the genes of the nodal and hedgehog signaling pathways (Roelink et al. 1994; Higashijima et al. 1997; Sampath et al. 1998; Lehmann and Naumann 2005) control the formation and function of cells that generate the RF such as the SCO (Sterba 1969; Oksche 1969), flexural organ (FO) (Olsson 1958), and floor plate (FP) (Rodríguez et al. 1996). The cells of the SCO (Gobron et al. 1996, 1999) and FP (Richter et al. 2001; Guinazu et al. 2002; Lehmann and Naumann 2005) synthesize and secrete the main component of the RFSCO-spondin. RF formation takes place by polymerization of SCO-spondin and depends on additional agents (Hoyo- 
Becerra et al. 2005), including clusterin (Clu) and galectin-1 (lgals1) (Muñoz et al. 2019). The human SCO secretes proteins that do not polymerize and remain soluble in the CSF (Oksche 1964; Rodriguez et al. 1993, 2001). The RF disassembles at the posterior end of the central canal (filum terminale) to form the mass caudalis (Olsson 1956; Chesler and Nicholson 1985; Oksche 1969; Rodríguez et al. 1987a).

The deficiency of RF and motile cilia affects the flow of the CSF and results in hydrocephalus and scoliosis (Cifuentes et al. 1994; Grimes et al. 2016). Hydrocephalus is a common phenotype caused by developmental defects in abnormal production of CSF by the ependyma or CSF flow (Jiménez et al. 2001; Zhang et al. 2006; Kahle et al. 2016; Shen et al. 2016). Hydrocephalus correlates with mental retardation, schizophrenia, and neurodegeneration (Angeloni et al. 1999; Frints et al. 2003; Schlatter et al. 2008; Senchenko et al. 2011; Alsanie et al. 2017). The CSF flow could be affected by the lack of communication between BVS cavities, defects of motile cilia, cardiovascular abnormalities, or deficiency of the choroid plexus (CP), SCO, and RF.

During neural development and regeneration, the proteins of the immunoglobulin superfamily play essential roles in cell-cell recognition and adhesion. These include mammalian L1-CAM, N-CAM, Nr-CAM, neurofascin, and a close homolog of L1-CAM (Chl1; Maness and Schachner 2007). In zebrafish, some of these genes exist as two copies due to partial genome duplication in teleosts, for example L1-CAM (llcama and l1camb), neurofascin (nfasca and nfascb), and Chl1 (chlla/camel and chl1b) (GRCz10, release 91). In embryonic zebrafish, the duplicated genes encoding L1-CAM (llcama and llcamb) express different differentiating neurons. The functional analysis showed the role of these genes during regeneration of the CNS and memory consolidation (Tongiorgi et al. 1995; Pradel et al. 2000; Becker et al. 2004). The levels of L1-CAM and N-CAM increased in the CSF of schizophrenic patients (Poltorak et al. 1997). The L1CAM mutations in humans cause the expansion of brain ventricles, hydrocephalus, mental retardation, and deficiency of corpus callosum (reviewed in Wong et al. 1995). In mammals, Chl1 acts in axonogenesis, whereas its deficiency causes mental retardation, schizophrenia, and neurodegeneration (Angeloni et al. 1999; Frints et al. 2003; Schlatter et al. 2008; Senchenko et al. 2011; Alsanie et al. 2017). Chl1 has been suggested as a susceptibility gene of adolescent idiopathic scoliosis in humans (Sharma et al. 2011), although other studies failed to support this link (Qiu et al. 2014).

Here, we report the developmental analysis of camel/ 'chlla' (https://www.ncbi.nlm.nih.gov/nuccore/EU560427) in zebrafish. Given its strong expression in the circumventricular organ (CVO) and axial structures, camel is a useful marker of the BVS development. Its maternal transcripts distribute uniformly, unlike the zygotic transcripts that demonstrate clearly defined expression pattern, in particular in the axial structures such as FP, hypochord ( $\mathrm{HC})$, and roof plate (RP), as well as several CVOs such as SCO and FO. Several splice variants of camel messenger RNA (mRNA) differentially enhance cell adhesion. The morpholino (MO)mediated knockdown of Camel affects cell adhesion and RF formation and cause hydrocephalus later on. Thus, Camel emerges as the potential regulator of cell adhesion linked to the morphogenesis of the RF and formation of the BVS.

\section{Materials and methods}

\section{Animals}

Zebrafish embryos were obtained from the zebrafish colony maintained according to IACUC rules at the Fish Facility of the Institute of Molecular and Cell Biology, Singapore. The stages of development were presented as hours post fertilization (hpf) at $28.5^{\circ} \mathrm{C}$ (Kimmel et al. 1995). All animal experiments were carried according to the regulations of the Institutional Animal Care and Use Committee (Biological Resource Center of Biopolis, license no. 120787), which approved this study. The zebrafish AB line was used as wildtype controls. The dominant-negative Notch mutant $m i b^{t a 52 b}$ was described (Itoh et al. 2003). The transgenic line sqet33mi2AEt (simplified as $\operatorname{Tg}($ ET33-mi2a) (http://zfin.org/ ZDB-ALT-110622-3) resulting from the large-scale enhancer-trap screen carries transposon insertion in the intron of promla (ENSDARG00000039966) (Kondrychyn et al. 2009). The GFP expression in this line maps to the RP and SCO. The transgenic enhancer-trap line sqet27Et (simplified here as ET27) (Parinov et al. 2004; http://zfin.org/ZDB-ALT110622-3) carries the transposon in the intron of pard3 (ENSDARG00000110804.1).

\section{Cloning and sequencing}

Complementary DNA (cDNA) m11 has been isolated fortuitously during isolation of zebrafish frizzled cDNAs (Emelyanov, unpublished). $\mathrm{Zg} 2$ and $\mathrm{Zg} 8$ corresponding to fragments of cDNA of frizzleds were used as probes to screen at low stringency the high-density arrayed cDNA library of zebrafish (stage 26 somites) containing cDNA inserts ligated into the vector pSport1 (Gibco BRL, USA) (Dheen et al. 1999), and m11 clone was subjected to the whole-mount in situ hybridization. The differentially transcribed isoforms of camel were synthesized as cDNA by RT-PCR (Suppl. Fig. 1 and 2) and cloned into the pCS2 vector for mRNA in vitro transcription using the mMessage mMachine $\mathrm{T} 7$ Transcription Kit (Thermo Fisher). Sequence analysis and compilations were performed using Gene Works and MacVector (Oxford Molecular Group, UK), SnapGene, and ClustalW software. The primers and cDNA sequences for 


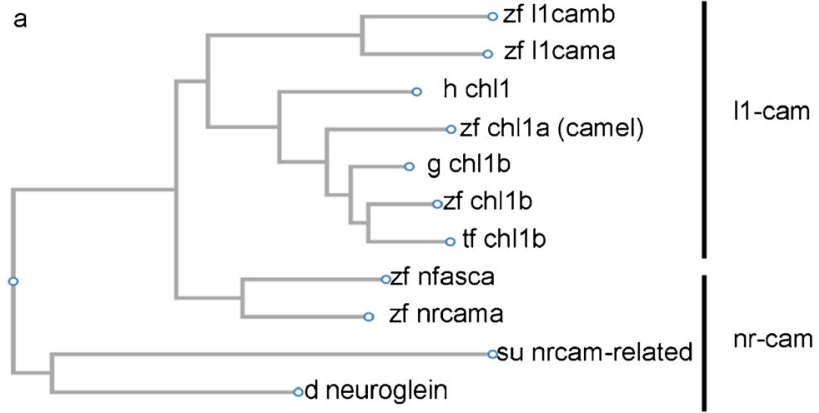

b

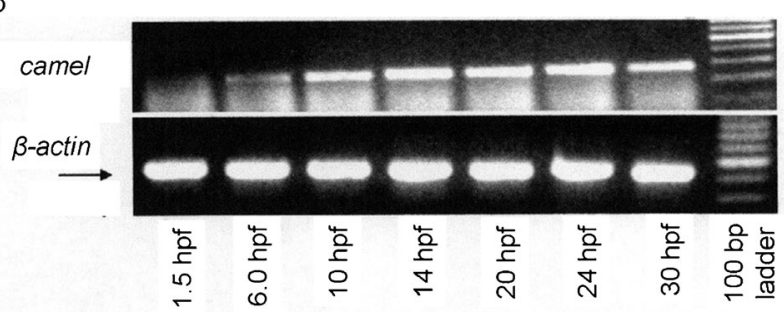

Fig. 1 The comparison of Camel to other proteins of L1-CAM family of proteins and camel expression during development. Camel is the more evolutionarily distant of the two duplicated Chl1-related proteins of zebrafish. a The dendrogram comparison of similarity within a group of vertebrate CAM, where the Camel protein forms a distinct group different from the "Chllb" one. b The temporal expression of camel during development as detected by RT-PCR. Abbreviations: d, Drosophila melanogaster; g, spotted gar (Lepisosteus oculatus); h, human (Homo sapiens); su, sea urchin (Strongylocentrotus purpuratus); tf, Takifugu rubripes; zf, zebrafish (Danio rerio)
mRNA isoforms are provided in the Supplementary Materials (primers and mRNA isoforms).

\section{Morpholino and mRNA microinjection}

All morpholino (0.2 pmol) and mRNA (100 pg) were injected at the 1-2 cell stage.

- MO1: 5'-CACTgAgACTCCTgAGCCCCCTCAT-3' (targets ATG site)

- MO2: 5'-gAgCTTCTTACCgACTCCTTCAAgA-3' (targets 5'-UTR, nt 55-79)

- MS1: 5'-AgCACgACTgAgAgAAATACAAAgA-3'

- MS2: 5'-ATCACCTggAggAATAACCgCATAT-3'

mRNA was synthesized from the linearized expression vector pCS2 using T7 mMessage mMachine (Amgen) in vitro transcription kit and aliquoted to be kept at $-80{ }^{\circ} \mathrm{C}$. For co-injection, the $\mathrm{MO}$ and mRNA were mixed prior to injection.

Once formed, the brain fourth ventricle (vIV) was injected for visualization of the BVS with $5 \mathrm{kDa}$ Texas Red at 20$22 \mathrm{hpf}$ as described in Shen et al. (2016).
Fig. 2 The expression pattern of camel during early zebrafish development detected by wholemount in situ hybridization. $\mathbf{a}, \mathbf{b}$ camel is inherited as a maternal transcript distributed uniformly. c During gastrula, the embryonic shield (ES, arrow) is stained more intensely compared to other regions. d During somitogenesis, the expression is largely in the ventral midline (arrowhead). Scale bar $=100 \mu \mathrm{m}$

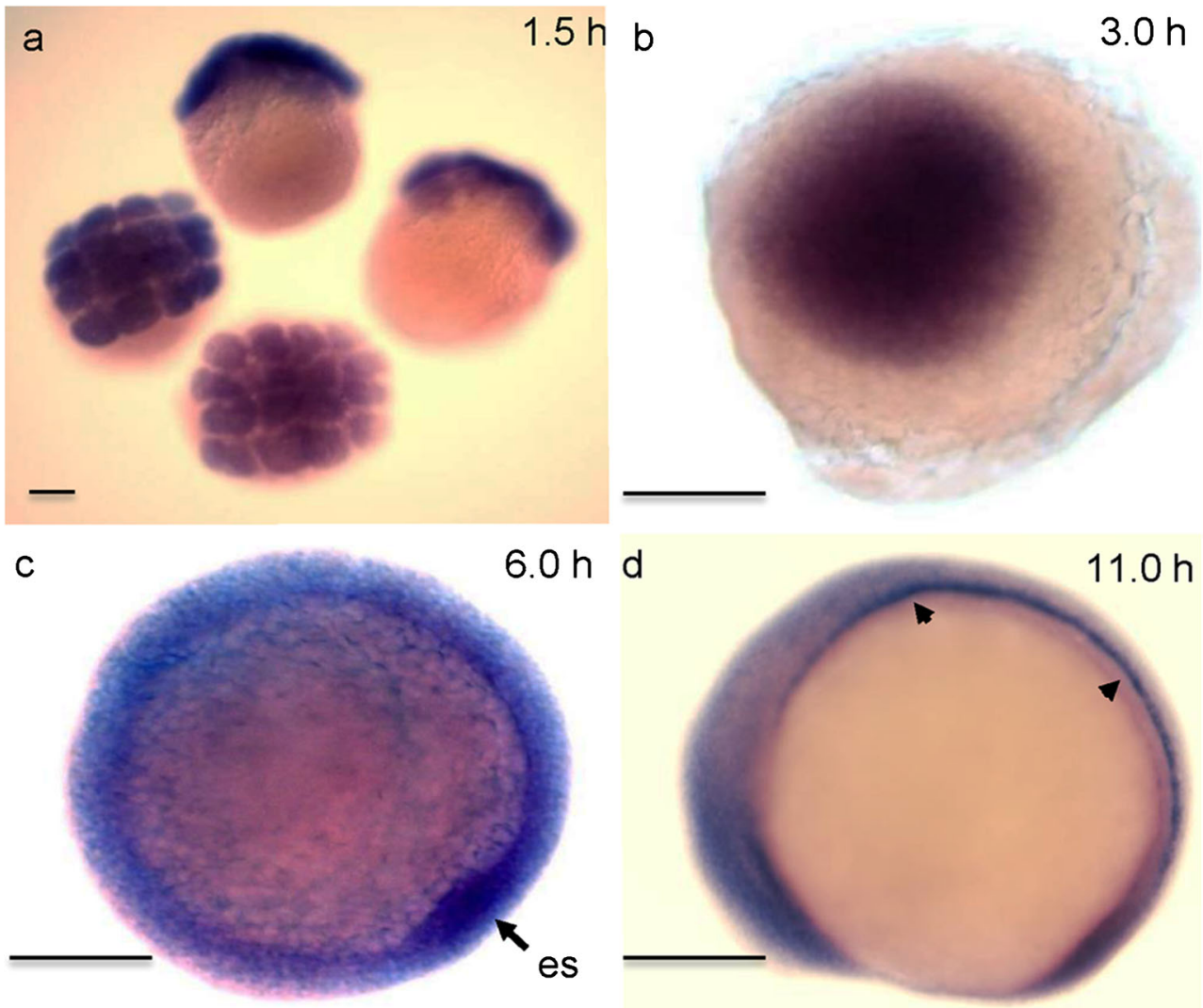




\section{RT-PCR}

Total RNA from embryos at selected stages was isolated using RNeasy Kit (Qiagen, Germany); $0.5 \mu \mathrm{g}$ total DNA-free RNA was used for multiplex RT-PCR using One-Step RT-PCR Kit ( Q i a g e ). The primers used FP 5'TgCAgCATTCgTgCTCAACgT-3' and RP 5'-AACA gCCgATgAggACAAgCA-3'. The wild-type PCR product was $368 \mathrm{bp}$. The zebrafish $\beta$-actin gene was used as a control. The primers used were $\beta$-actin, forward $5^{\prime}$ TggCATTgCTgACCgTATgC-3' and reverse 5'gTCATggACgCCCATTgTgA-3' (FP1/RP1, 450 bp). The control PCR for DNA contamination was performed without RT step. The annealing temperature for PCR was $55^{\circ} \mathrm{C}$. The aliquots of PCR mixture were removed after 25, 30, and $35 \mathrm{cy}-$ cles to determine that the fragments were in the exponential phase of amplification. The position of primers for amplification of different regions of camel and its isoforms are shown in Suppl. Fig. 1 and 2.

\section{Whole-mount in situ hybridization and immunostaining}

Whole-mount in situ hybridization (WISH) using RNA probes labeled with digoxigenin (Dig; Roche, USA) was carried out as previously reported by Oxtoby and Jowett (1993). The embryos were stained by the two-color immunohistochemistry for GFP and RF using mouse anti-GFP Mab and polyclonal rabbit AFRU antibody (1:1000) (a gift of Drs. J. Grondona [Malaga, Spain], E. Rodriguez, and M. Guerra [Valdivia, Chile]) according to the described protocol (Korzh et al. 1998).

\section{Microscopy}

The embryos stained using WISH were prepared and observed using differential interference contrast (DIC) microscopy as described before (Korzh et al. 1998).

The temperature of the confocal microscope chamber was maintained at $28{ }^{\circ} \mathrm{C}$ during image acquisition. Imaging was performed using the microscope Zeiss LSM 800 with Airyscan (Carl Zeiss, Germany); 488-nm and 561-nm lasers were used to excite fluorescence with emission detected using emission filters (505-545 $\mathrm{nm}$ and 575-615 nm BP), respectively. Data were saved in the CZI format and then processed using ImageJ $1.51 \mathrm{n}$ software (Fiji). For each, z-stack average intensity and sum slice projections were generated.

\section{Hanging-drop cultures}

Hanging-drop cultures were carried out with animal caps from embryos at $50 \%$ epiboly as previously described (Steinberg and Takeichi 1994; Fong et al. 2005). Fluorescent images were obtained with a Zeiss Axioplan 2 equipped with a Zeiss AxioCam HRc CCD camera (Zeiss, Germany).

\section{Results}

\section{Camel cloning and sequence analysis}

We fortuitously isolated a partial fragment of cDNA during a low stringency screen of the 26-somite wild-type zebrafish high-density arrayed cDNA library using probes for zebrafish frizzleds (Emelyanov et al., unpublished). The library contained cDNA inserts ligated into the vector pSport1 (Gibco BRL, USA) (Dheen et al. 1999). BLAST analysis demonstrated that the partial cDNA clone is distantly related to the mammalian L1-Cam family of genes. Using PCR amplification, we generated the full-sized cDNA of this gene (GenBank acc. no. EU560427). The putative protein has $45 \%$ homology with human and mouse L1-CAM and 46\% homology with human CHL1. Therefore, we named it Camel (CAM-L1-related). The BLAST against the zebrafish genome mapped the gene into the position of chlla (ENSDARG00000077881). A later analysis demonstrated a presence in the genome of the second ohnolog-chllb. It seems that the order of identification of these genes predetermined an extension assigned to their names- "a" and "b." The relatively evolutionary "primitive" spotted gar genome Lepisosteus oculatus had no teleostean duplication (Braasch et al. 2016). It contains a single chllb similar to the chllb of zebrafish and much less so to the camel/chlla. The single chllb of gar and other fish species without genome duplication should be renamed as chll (Gasanov et al. 2020, unpublished). In the species, where a pair of ohnologs exists, the chll genes must be renamed reciprocally similar to many other ohnologs that were misnamed as suggested by the evolution-based systematic synteny analysis. Hence, camel should be renamed as camel/chllb. Here, we refer to this gene as camel.

\section{Expression of camel during development}

The RT-PCR revealed the temporal expression pattern of camel mRNA at 1, 5, 6, 10, 14, 20, 24, and $30 \mathrm{hpf}$. It detected the presence of the maternal transcripts (Fig. 1b) and an increase in camel expression in a whole embryo starting from $6 \mathrm{hpf}$ (Fig. 1b). The WISH revealed the spatial distribution of camel transcripts. Their relatively uniform distribution was detected until the beginning of somitogenesis when the anterior neural tissue and axial structures became labeled more intensely (Fig. 2a-d). In the head, at $17 \mathrm{hpf}$, camel was expressed more intensely in the forebrain and in the trunk (HC and FP) (Fig. 3a, c). 
Fig. 3 The expression pattern of camel in wild-type embryos and mutants detected by whole-mount in situ hybridization during neurogenesis. camel is expressed in the axial structures (fp, rp, hp), along segmental boundaries in the brain and in circumventricular organs. a, c $17 \mathrm{hpf}$, wild-type embryos. b, d 17 hpf, mib $b^{\text {tas2b }}$ mutant. e, g 24 hpf, wild-type embryos. f $24 \mathrm{hpf}, \mathrm{mib}^{\text {ta } 52 b} \mathrm{mu}-$ tant. h 36 hpf, brain of a wild-type embryo. i Wild-type trunk, 48 hpf. h, j Wild-type brain, 48 hpf. Numbers define rhombomeres of the hindbrain, asterisk indicates gaps in the floor plate, and arrow indicates remains of hypochord. $\mathbf{a}, \mathbf{b}, \mathbf{e}, \mathbf{f}$ Dorsal view. $\mathbf{c}, \mathbf{d}, \mathbf{g}-\mathbf{j}$ Lateral view. Abbreviations: ahp, adenohypophysis; $b$, brain; c, cerebellum; $\mathrm{d}$, diencephalon; e, epiphysis; emp, eminentia thalami; epIII, ependyma of the third ventricle; ey, eye; hb, hindbrain; ht, hypothalamus; fo, flexural organ; fp, floor plate; hb, hindbrain; hc, hypochord; ht, hypothalamus; me, median eminence; mrp, midbrain roof plate; not, notochord; ot, optic tectum; ov, otic vesicle; ovlt, organum vasculosum lamina terminalis; pvo, paraventricular organ; rp, roof plate; sc, spinal cord; sco, subcommissural organ; $\mathrm{t}$, telencephalon; tg, tegmentum. Scale bar $=100 \mu \mathrm{m}$
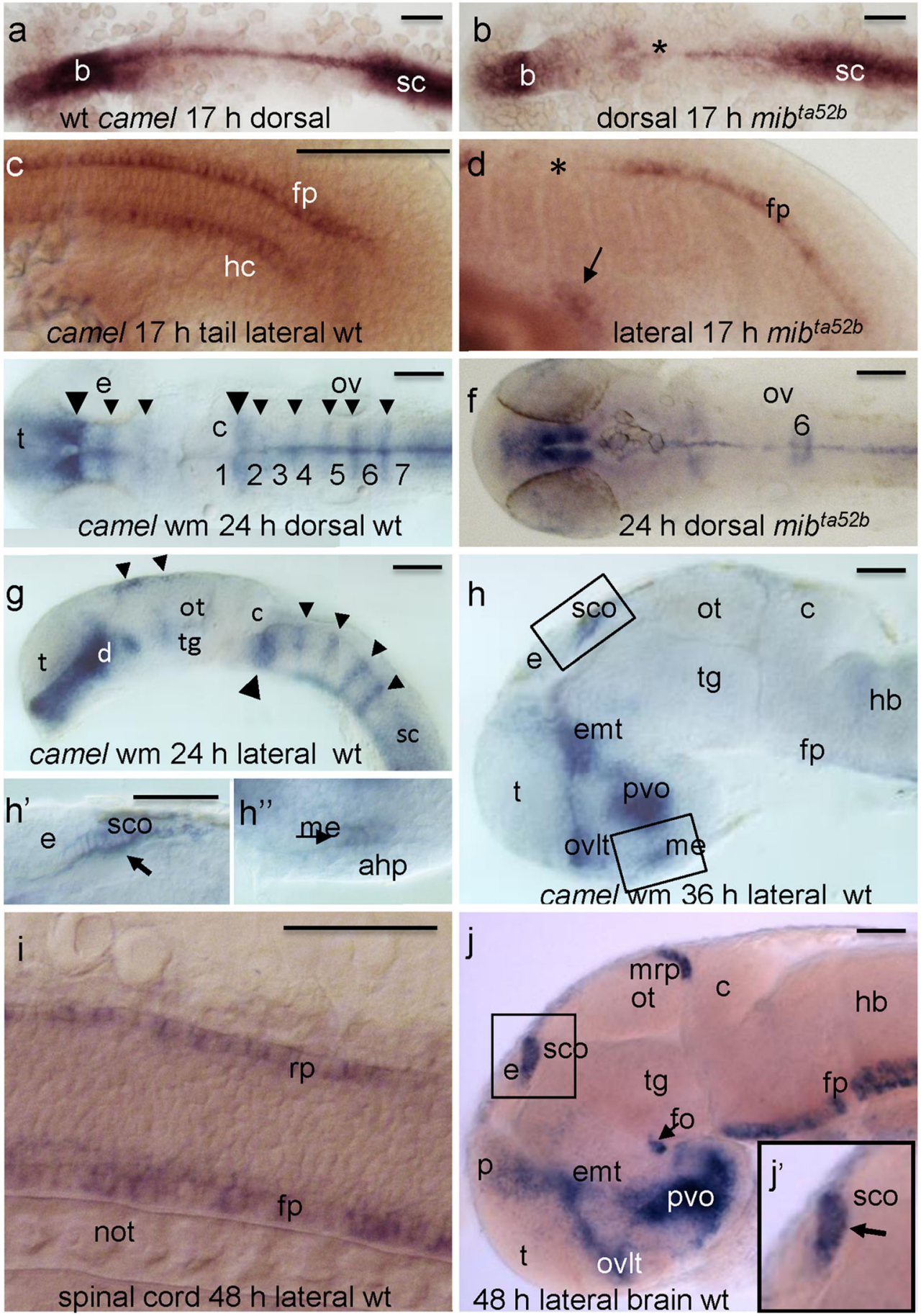

Interestingly, this expression pattern has changed substantially in the dominant-negative Notch mutant $m i b^{t a 52 b}$ characterized by the ectopic activity of delta (Itoh et al. 2003) (Fig. 3b). Here, the expression in the $\mathrm{HC}$ was absent, but some disorganized cells, probably representing remains of this structure, were detected close to the anus (Fig. 3d, arrow). This observation is in line with earlier results showing the role of notch signaling during $\mathrm{HC}$ development (Latimer and Appel 2006).
At $24 \mathrm{hpf}$, camel expression was found in the ventral diencephalon, hindbrain inter-rhombomeric boundaries, and midbrain RP (Fig. 3e, g). The WISH analysis of 24-hpf mutant $m i b^{t a 52 b}$ revealed an absence of expression at most interrhombomeric boundaries, excluding the boundary of rhombomeres 1-2 and borders of rhombomere 6 (Fig. 3f). This observation suggested that Camel may act in the maintenance of neural progenitors at these boundaries (Itoh et al. 2003; Wang et al. 2003). At 24-36 hpf, the most anterior 
portion of the midbrain RP started to change its relatively straight linear organization (Fig. 3g, h, h'). It bends and bulges ventrad (Fig. 3h', arrow). By 48 hpf, these cells become much more elongated (Fig. 3j, j'), compared to other regions of RP.

At $36 \mathrm{hpf}$, camel expression associated with the BVS is obvious. Based on cell morphology and neuroanatomical landmarks and recent analysis (García-Lecea et al. 2017), the domain corresponding to the most anterior midbrain RP (posterior to epiphysis) corresponds to the SCO (Fig. 3h, h'). The expression domain immediately above the adenohypophysis corresponds to the median eminence (ME; Fig. 3h, h"). Note the characteristic linear distribution of cells in the SCO and ME (Fig. 3h', h") along the anterior-posterior axis reminiscent of that in the RP and FP (Fig. 3i). The expression domain at the floor of the vIII in the preoptic area most likely corresponds to the organum vasculosum lamina terminalis (OVLT). The domain in the hypothalamus posterior to the OVLT and dorsal to the ME may represent the paraventricular organ (PVO; Fig. 3h, j). The SCO, ME, OVLT, and PVO are CVOs of zebrafish - specialized areas of the blood-brain-CSF barriers involved in the communication between the brain, CSF, and blood (Tsuneki 1986; Joly et al. 2007; GarcíaLecea et al. 2017). All domains associated with the vIII are connected by expression in ependymal cells lining the ventricle (Fig. 3h, j). camel is still expressed in all these regions at 48 hpf.

At this stage, camel expression is clearly defined in the FP and its most anterior region, the FO. The most posterior midbrain RP (mRP) bends to form the midbrain-hindbrain boundary (MHB) (Fig. 3j). These expression domains remain during the post-embryonic period at $72 \mathrm{hpf}$ (Fig. 4a). By that stage, the identical cuboid cells of the anterior mRP, first seen at $24 \mathrm{hpf}$, become elongated (36-48 hpf) and form the triangular iron-shaped pocket of cells folded in the middle (Fig. 4a', arrow). It looks like the mid-part of this cluster is being pulled towards posterior. Here, camel expression is more intense compared to the rest of the mRP. At $48 \mathrm{hpf}$, camel retinal expression is restricted to the ventro-rostral patch known as a site of initiation of retinal differentiation (Fig. 4b) (Larison and Bremiller 1990; Korzh et al. 1998; Neumann and Nusslein-Volhard, 2000). As differentiation of retinal cells progresses at $72 \mathrm{hpf}$, the camel expression domain covers most of dorsal retina (Fig. 4c). Other regions of expression at $48 \mathrm{hpf}$ are represented by the heart (not shown). Hence, during neural development, the expression of camel takes place in several structures associated with the BVS.

\section{Camel isoforms differ at the level of the most C- terminal fibronectin type III domain}

The variation in the cDNA sequence suggested that several isoforms of camel may exist due to differential splicing. We cloned them by PCR and found four camel transcripts that vary due to differential splicing of exons 24 and 25 (Fig. 5a, Suppl. Fig. 1) encoding the most C-terminal fibronectin (FN) type III domain (VIth). This may result in proteins with or without the whole domain or presence of one of its two halves (Fig. 5b).

\section{camel regulates cell adhesion in vitro}

Camel belongs to a superfamily of L1-CAM-related molecules implicated in cell adhesion (Crossin and Krushel 2000; Maness and Schachner 2007). In human, L1-CAM LOF mutations cause X-linked hydrocephalus (OMIM \#307000), and deficiency of this gene in Xenopus and mice also causes hydrocephalus (Rolf et al. 2001; Date et al. 2019). In human, CHL1 deficiency has been linked to cancer (Senchenko et al. 2011). Being a member of the class of neural CAMs, Camel may play a role in cell adhesion during development. To check this idea, the "hanging drop" assay (Steinberg and Takeichi 1994; Redies 2000; Fong et al. 2005) has been performed in combination with the MO-mediated knockdown of Camel. The pan-Camel MO (MO1-2) (Fig. 5a, Suppl. Fig. 2) and $\mathrm{MO}$ complementary to different regions of camel mRNA, including those blocking specific isoforms (MS1-2), have been used (Fig. 5a).

The two different color dextrans were injected into embryos: one of the two groups of embryos used as a control and the second group co-injected with different anti-Camel MOs. The cells were isolated at 6-hpf stage, dissociated, mixed in equal proportion, and cultivated in hanging drops overnight. The control cells of two different colors formed uniformly mixed clusters (Fig. 6a). In contrast, when the pan-Camel MO (MO1 or MO2) was used and morphant cells (red) were mixed with control ones (green), the two types of cells formed distinct clusters of different colors (Fig. 6b, c, f) in the indication of different types of cell adhesion.

Distribution of cells caused by the isoform-specific MOs differs. MS1 blocks isoforms 1 and 3, which might leave isoforms 2 and 4 intact. MS2 blocks isoforms 1 and 2, leaving isoforms 3 and 4 intact. A combination of MS1 and MS2 targeted isoforms 1-3, leaving only isoform 4 intact (Fig. 5a, b). With single MO, the cells of one color formed the core and cells of another color attached at the periphery (Fig. 6d, e) in an indication of the different adhesion levels. This suggested a specific role for isoforms 2 and 3 encoding proteins containing different parts of the variable fibronectin type III domain (Fig. 5). The combination of MS1 and MS2 showed a phenotype similar to that of pan-Camel MO (Fig. 6f). Hence, in early development, Camel regulates cell adhesion. Its specificity may depend on the modification of the $\mathrm{C}$-terminal fibronectin type III domain.

The FGF signaling plays a role in cell adhesion during development (Ben-Hur et al. 1998; Gallegos et al. 2019). Direct CAM-FGFR interaction has been suggested (Doherty 
Fig. 4 The expression pattern of camel during late development. camel expresses in the brain ventricular system,

circumventricular organs, ventrorostral patch (vrp), and the eyedifferentiating retina. All images are in the lateral view. a $72 \mathrm{hpf}$, wild-type larvae. b $48 \mathrm{hpf}$, the left-hand side eye of the wild-type embryo. c $72 \mathrm{hpf}$, the left-hand side eye of the wild-type larvae. Abbreviations: c, cerebellum; chf, choroid fissure; cf, cephalic flexure; d, diencephalon; e, epiphysis; emt, eminentia thalami; fo, flexural organ; hb, hindbrain; ht, hypothalamus; mhb, midbrainhindbrain boundary; mrp, midbrain roof plate; op, olfactory placode, ot, optic tectum; ovlt, organum vasculosum lamina terminalis; pvo, paraventricular organ; sco, subcommissural organ; $\mathrm{t}$, telencephalon; tg, tegmentum. Scale bar $=100 \mu \mathrm{m}$ except a', where it is $25 \mu \mathrm{m}$
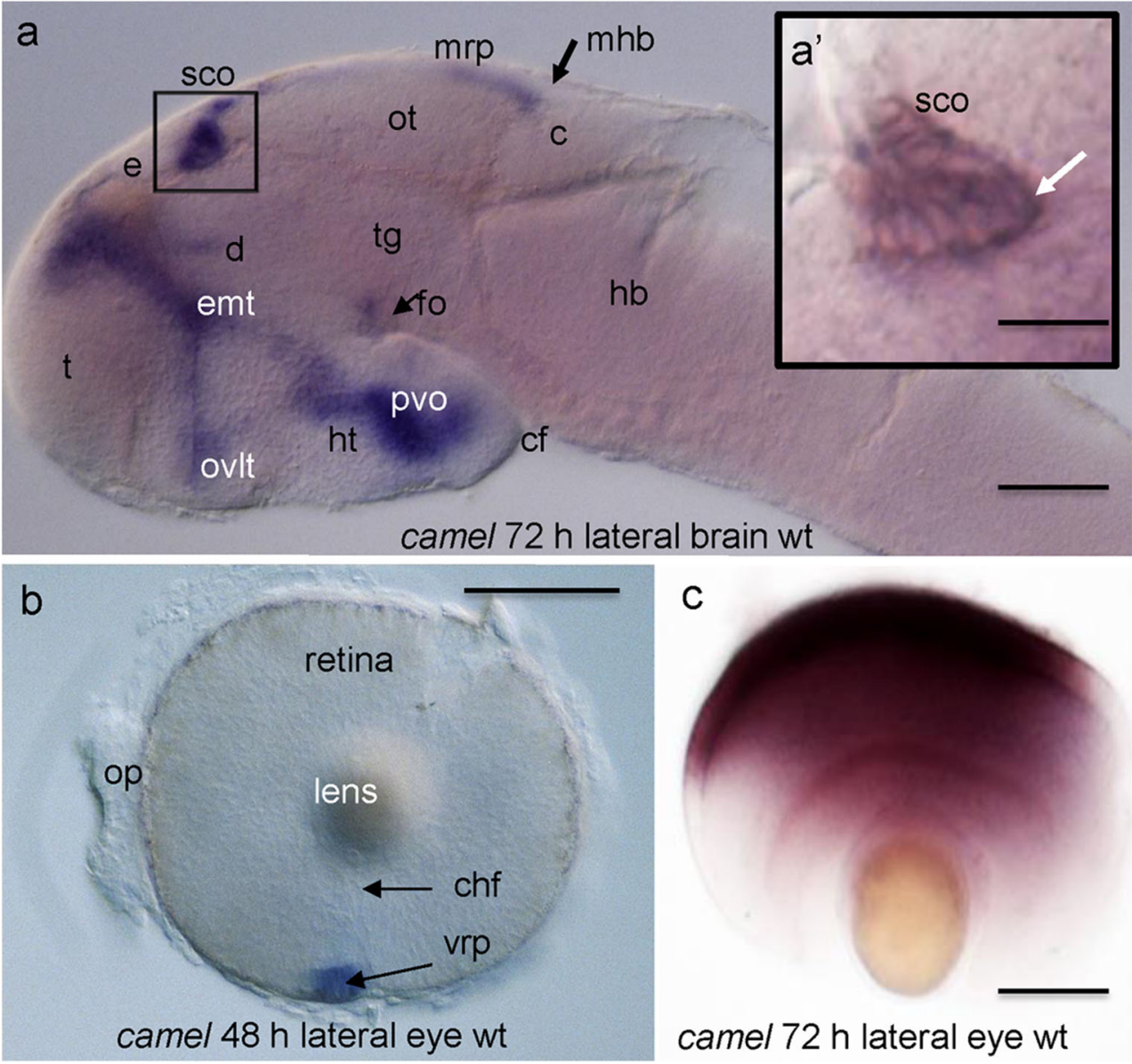

camel $72 \mathrm{~h}$ lateral eye wt

Fig. 5 The schematics of organization of the camel genomic DNA and four differentially spliced isoforms. The putative proteins encoded by these mRNA isoforms vary at the level of the fourth fibronectin type III domain encoded by exons 24 and 25. a Organization of camel genomic DNA showing the target sites for morpholino and colorcoded exons 24 (yellow) and 25 (blue). b Organization of the putative camel isoforms. The two halves of the sixth fibronectin type III domain are color-coded according to a. The Camel domain structure is generated using this software (http://expasy.org/ prosite)

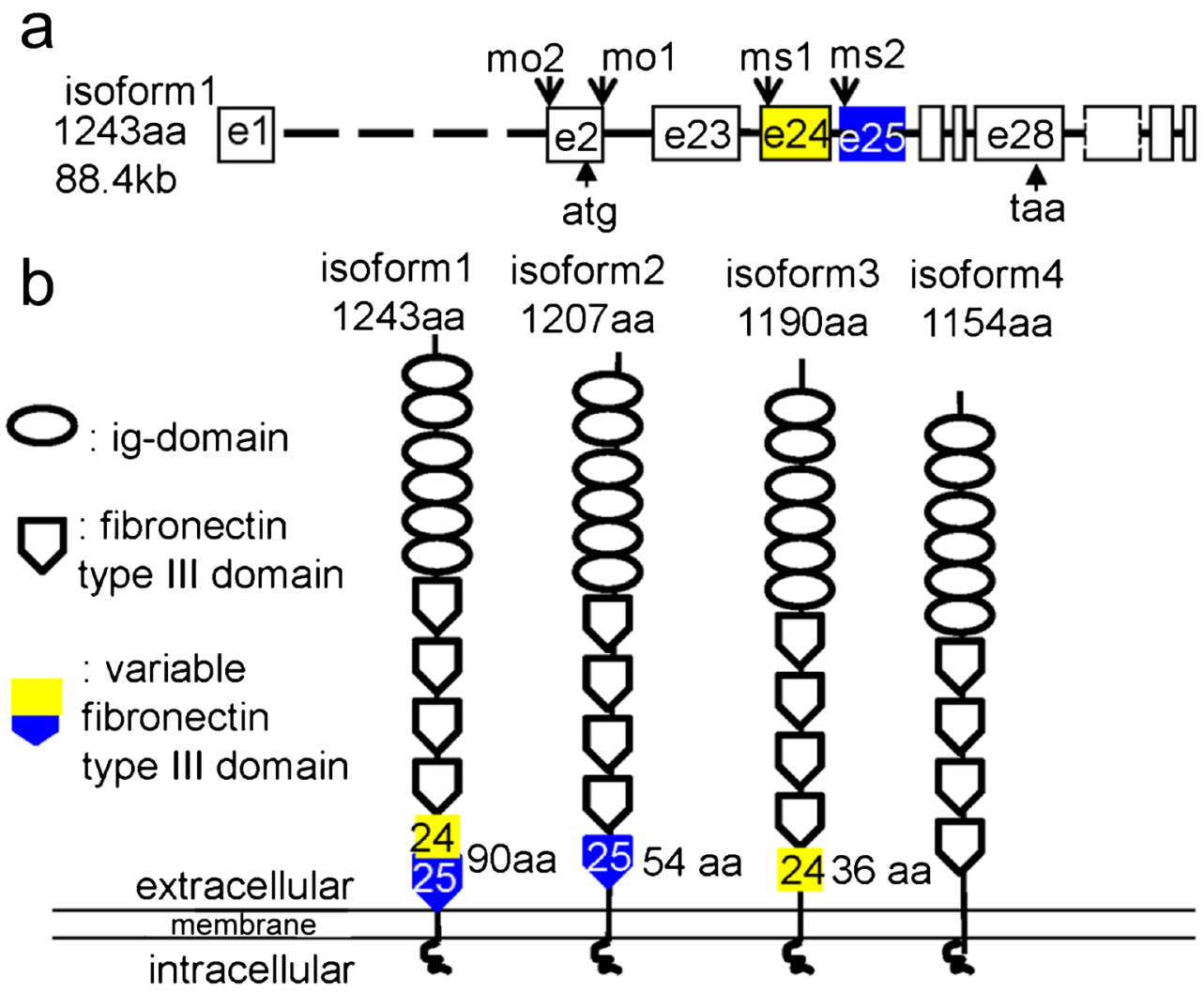



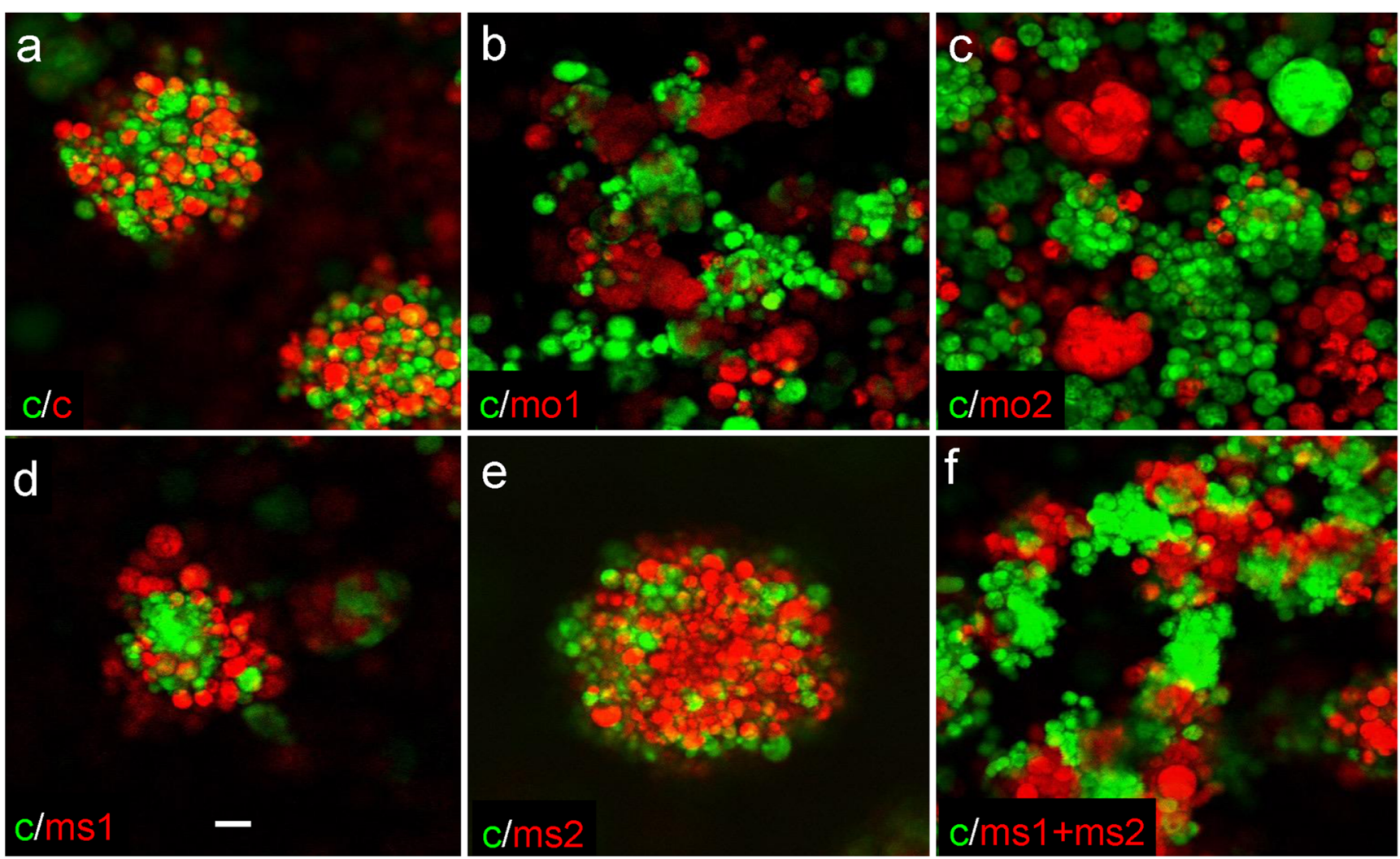

Fig. 6 a-f Camel regulates cell adhesion in hanging drops. The control cells of different-color formed clusters mixed uniformly, unlike those in experimental conditions when Camel expression was affected in red cells by the anti-Camel morpholino. c (red, green), control; MO1 and MO2,

and Walsh 1996) between the FN3 domains I-V of the similarly organized L1-CAM and FGFR1 (Kulahin et al. 2008). Possibly, a variation in the FN3 domain VI of Camel may affect this potential interaction.

\section{Camel loss-of-function in vivo}

To address a function of Camel during development, we microinjected the 1-2 cell-stage zebrafish embryos with the antisense oligomers (MO) against different regions of camel mRNA, including those blocking specific isoforms (see below), and raised them to different developmental stages. The pan-anti-Camel MO (MO1) caused a dose-dependent deficiency of the brain, including hydrocephalus, and curled trunk (Fig. 7b, Table 1). This phenotype has been defined previously as a hallmark of deficiency of CSF flow (Grimes et al. 2016; Boswell and Ciruna 2017; Sternberg et al. 2018). The isoform-specific MOs have a mild effect (Fig. 7c, d, Table 1), which increased when these MO were combined (Fig. 7e).

Early and new evidence strongly indicates that straightening of the body axis is RF-dependent (Kondrychyn et al. 2013; Cantaut-Belarif et al. 2018; Troutwine et al. 2020; Vesque et al. 2019, unpublished). Therefore, our findings that the
pan-Camel morpholino; MS1, isoform 1,3-specific morpholino; MS2, isoform 1,2-specific morpholino. The combination of MS1 + MS2 blocks isoforms $1-3$. Scale bar $=20 \mu \mathrm{m}$

deficiency of CHL1-related Camel causes the phenotype in the developing zebrafish usually associated with scoliosis support an idea of Sharma et al. (2011) that a deficiency of CHL1 may be linked to adolescent idiopathic scoliosis.

\section{camel regulates formation of BVS in vivo}

To compensate for the inhibitory effect of MO, mRNA overexpression was used in the phenotype-rescue experiment. We focused on hydrocephalus, a phenotype that is easy to recognize and score (Shen et al. 2016). Different combinations of anti-pan-Camel and isoform-specific Camel MO and mRNA encoding different camel isoforms were injected (Fig. 5). As expected in all cases, the embryos injected with the antiCamel MO (camel morphants) developed hydrocephalus (Fig. 8a-d), whereas mRNA compensated this effect to a different degree in an indication of specificity of MO effect (Fig. 8f-h).

Interestingly, Camel GOF in control embryos resulted in the reduced BVS (Fig. 8a, e). This added evidence to support the role of camel in maintaining tissue integrity during the formation of BVS by increasing cell adhesion. While this was not unexpected given the role of cell adhesion in the formation of the neural tube (Maness and Schachner 2007; 
Fig. 7 a-e The effect of different anti-camel MOs varies depending on the target. MO1 targets all isoforms causing the most severe effect, including the

hydrocephalus, curled trunk, and edema. MS1 and MS2 target specific mRNA isoforms $(1+3$ and $1+2$, correspondingly). MS1 causes the hydrocephalus and mildly curled trunk. MS2 causes hydrocephalus. The effect of MS1 and MS2 is additive in enhancing the trunk curvature. 50 embryos were observed in each experiment repeated three times. The phenotypes representing $95 \%$ of experimental animals were selected. Scale bar $=50 \mu \mathrm{m}$
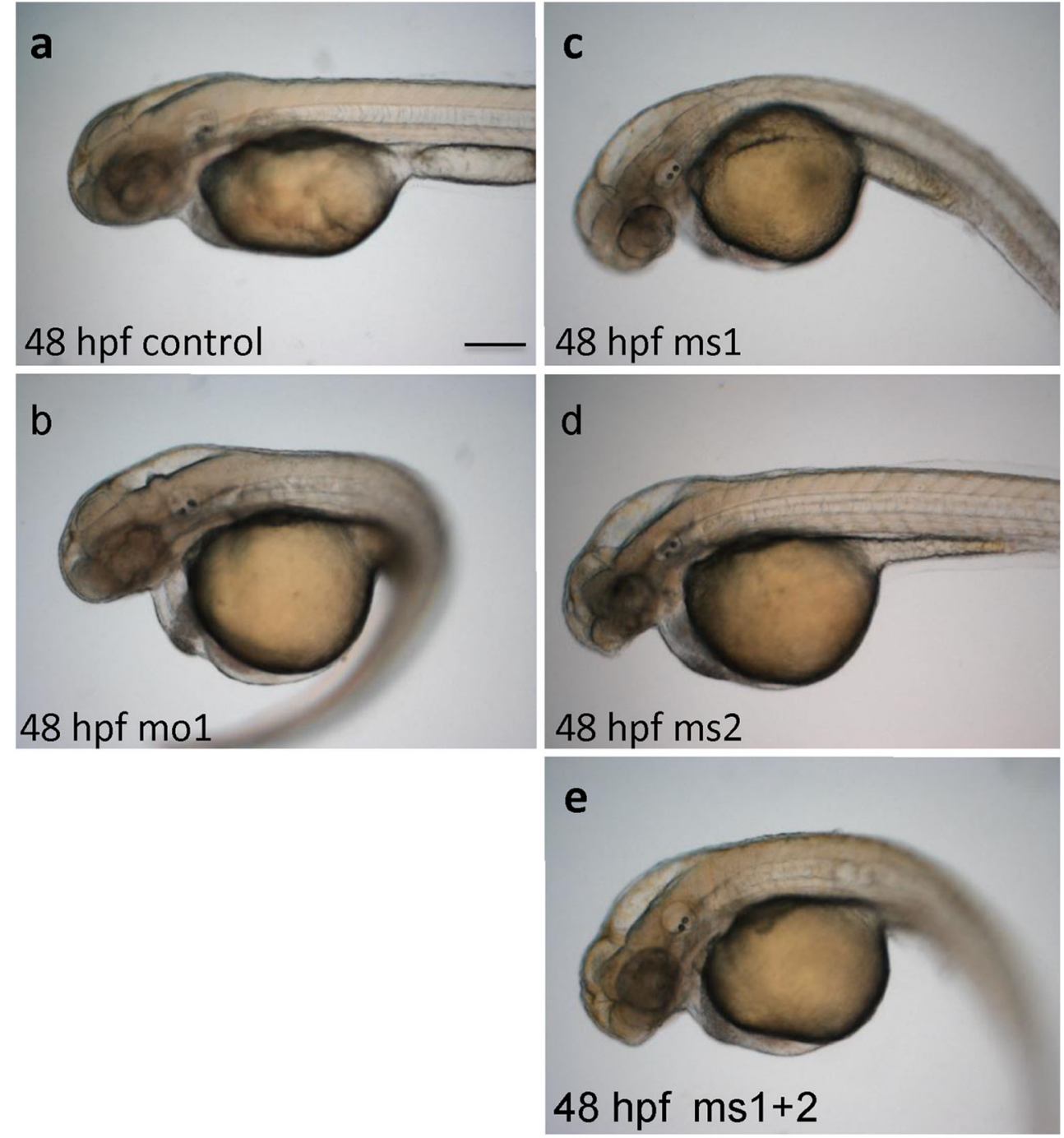

Fame et al. 2016; Shen et al. 2016), it raised a question of how Camel regulates the BVS development.

\section{camel and the Reissner fiber}

camel expresses in the SCO, FO, and FP, i.e., structures participating in the formation of the RF by continuously secreting into the CSF proteins that aggregate into microfilaments that become densely packed in a single fiber (Muñoz et al. 2019). The ever-growing RF extends from the SCO through the whole length of the spinal cord. A deficiency of RF has been linked to hydrocephalus (Meiniel et al. 2008; Jiménez et al.
2001; Wagner et al. 2003). Hence, we decided to explore a connection between camel, SCO, and RF. The AFRU antibody recognizes SCO-spondin (Rodríguez et al. 1984; Nualart et al. 1998), a product of SCO, FO, and FP. It specifically detects the RF, which polymerizes into several microfilaments in turn, assembled into a single thread-like structure of RF (Sterba 1969; Rodríguez et al. 1992).

The ET27 transgenics (Parinov et al. 2004; Kondrychyn et al. 2009; García-Lecea et al. 2017) express GFP in the SCO (Fig. 9a). When the control ET27 embryo is stained with AFRU antibodies, the signal can be detected at the SCO (Fig. 9b). This AFRU+ material is fibrous in controls

Table 1 Morphant phenotype

\begin{tabular}{llll}
\hline & MO1 $(n=48 / 50)$ & MS1 $(n=45 / 50)$ & MS2 $(n=42 / 50)$ \\
\hline Brain & Reduced, hydrocephalus & Reduced, hydrocephalus & Reduced, hydrocephalus \\
Eye & Reduced & Reduced & Reduced \\
Trunk & Curly & Slightly curly & Straight \\
\hline
\end{tabular}



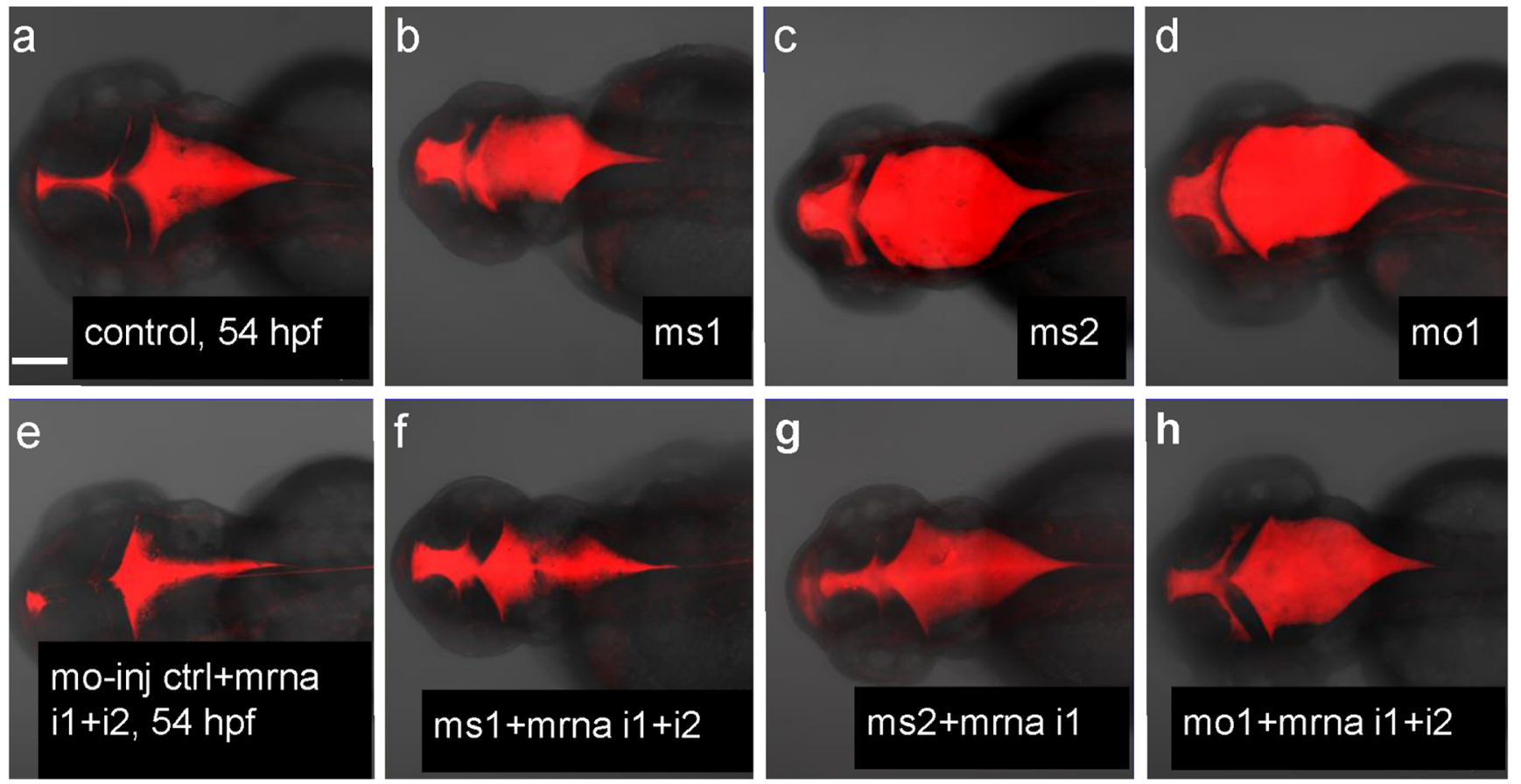

Fig. 8 Rescue of hydrocephalus in Camel morphants by camel mRNA. a Control. b-d Morphants with brain ventricles filled-in by Dextran-Texas Red. e Control wild-type embryo injected by camel mRNA. Notice that the size of the ventricular system is reduced compared to the intact

control. $\mathbf{f}-\mathbf{h}$ Different morphants rescued by injection of different camel mRNA isoforms. All images are dorsal views of 54-hpf embryos with anterior to the left. Scale bar $=100 \mu \mathrm{m}$

(Fig. 9b'), consistent with prior observations in other species (Rodriguez et al. 1986, 1987b).

When injected with the pan-anti-Camel morpholino (MO1), the SCO of morphants fails to develop its characteristic iron-like shape (Fig. 9c). In contrast to controls, the RF in morphants fails to form, whereas the dotted and amorphous signal can be detected at the SCO (Fig. 9d, d').

The RF could be formed not only by secretion from SCO but also with an additional contribution of the FO and FP (Olsson 1956; Yulis et al. 1998). To be able to observe these structures, we repeated the anti-RF staining in the $\operatorname{Tg}(\mathrm{ET} 33-$ mi2a) transgenics with GFP expression in the SCO, FO, and FP (Kondrychyn et al. 2009, 2011). This staining demonstrated the presence of the RF+ material on the apical surface of the SCO (Fig. 10a, a'), FO (Fig. 10a, a"), FP (Fig. 10a"'), and filum terminale (Fig. 10a"'). Following that, we repeated the MO-mediated Camel LOF in the Tg(ET33-mi2a) transgenics. An injection of the anti-pan-Camel MO (MO1) changed the shape of SCO and inhibited the formation of RF in the $\operatorname{Tg}$ (ET33-mi2a) transgenic morphants (Fig. 10b-b"'). This change may happen because of the deficient secretion of SCO-spondin or absence of galectin- 1 and clusterin that were suggested to regulate an assembly of the RF (Muñoz et al. 2019). In the SCO, FP, and FO of morphants, the amount and intracellular and extracellular distributions of RF+ material were abnormal (Fig. 10b', b", b"'). The AFRU+ material in the filum terminale was barely noticeable (Fig. 10b"').

The isoform-specific morpholinos MS1 and MS2 partially inhibited the formation of RF (Fig. 10c-c'"', d-d'"'), indicating that secretion of the RF+ material depends on the combination of several camel isoforms. At the same time, the phenotypes caused by MS1 and MS2 differ. MS1 caused a general reduction of AFRU staining without affecting the distribution of RF+ material (Fig. 10c-c'"'). Whereas MS2 not only caused a general reduction of staining, RF material was found in the anterior vIII and associated with the mRP (Fig. 10dd'"'); i.e., the RF+ material was significantly redistributed. These results demonstrated that Camel LOF affects the formation of RF.

\section{Overexpression of camel affects the distribution of RF+ material}

Thus, Camel LOF causes a defect of RF, which correlates with hydrocephalus. Camel gain-of-function (GOF) rescues hydrocephalus. Therefore, we checked the effect of camel mRNA microinjection, which causes the pan-embryonic Camel GOF, on the development of the BVS. An excess of RF material makes it challenging to ascertain the shape of SCO at $72 \mathrm{hpf}$ (Fig. 11). The trajectory of anterior RF between SCO and FO is no longer straight. In the mildly affected larva, the RF+ material is in ectopic locations, the apical surface of the dorsal midline, and choroid plexus of the fourth ventricle (CPIV) (Fig. 11h). In the severely affected larvae, the additional 
Fig. 9 Camel required for the development of SCO and formation of Reissner fiber. $\mathbf{a}, \mathbf{b}$ Control. c, d Pan-anti-Camel morphants (MO1). All images are of ET27 transgenics at 48 hpf. a, c In vivo images of GFP expression. $\mathbf{b}, \mathbf{d}$ Double immunostaining for GFP and Reissner fiber. b', d' Blowup of boxed areas in b and d, respectively. b' The AFRU staining in controls is mostly presented by the filamentous extracellular material with gaps between SCO and AFRU material (arrow) and in the AFRU material (arrowhead). Some faint AFRU staining was detected in the cytoplasm (asterisk). d' In morphants, the AFRU material is disorganized; it covers the SCO more with some residual signal in the cytoplasm (asterisk). Scale bar $=100 \mu \mathrm{m}(\mathbf{a}-\mathbf{d})$ and $50 \mu \mathrm{m}$ (b', d')
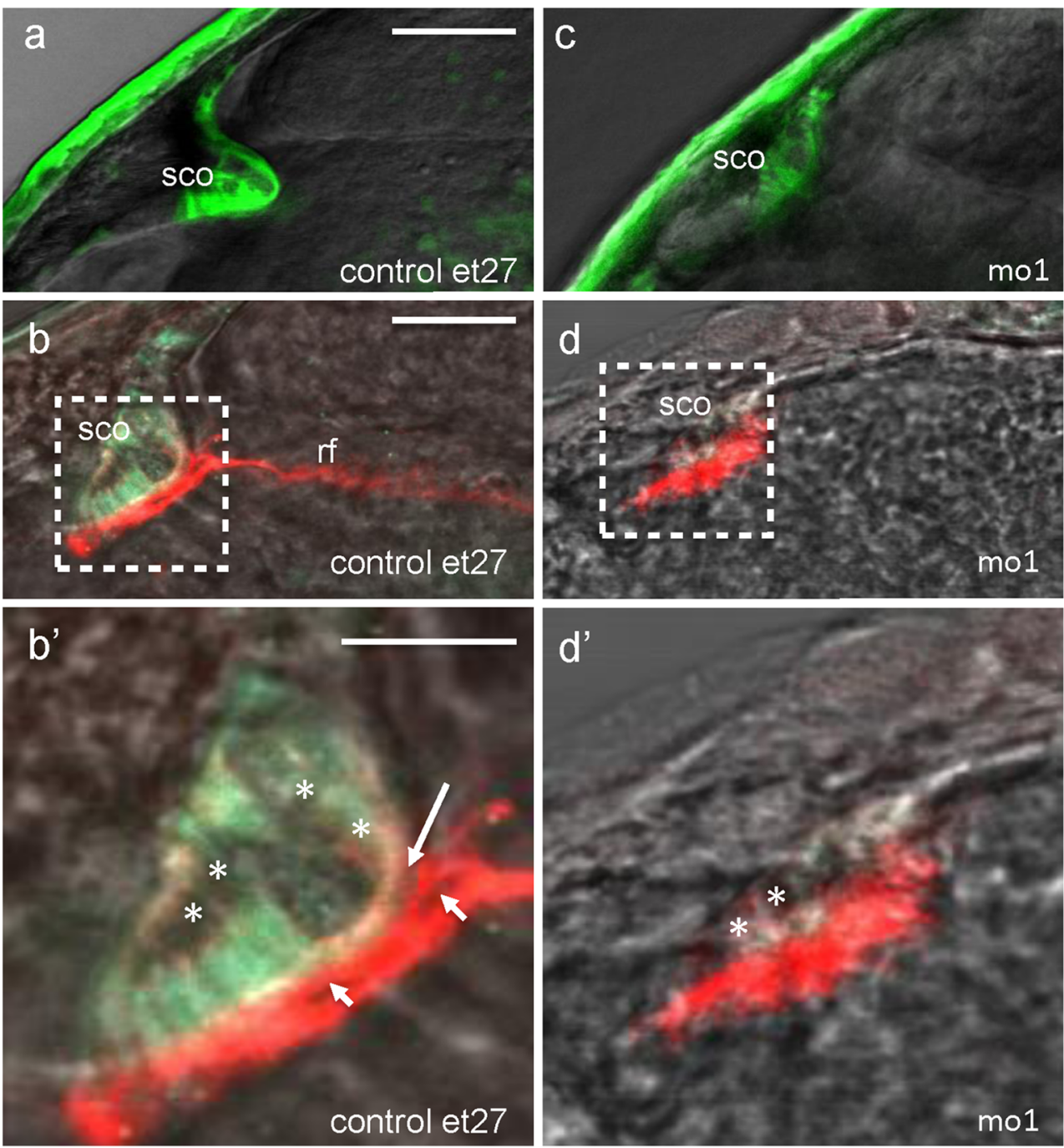

sprouts of the RF are dorsad of FO. The RF connects to the CPIV. Posteriorly, the RF retakes its route alongside the FP and enters the central canal of the spinal cord (Figs. $11 \mathrm{~g}$ and 12b). An ectopic RF material covers the surface of ependyma in vIII and vIV. The Camel LOF and GOF experiments demonstrated that the formation of RF depends on Chl1-related Camel.

\section{Discussion}

The deficiency of the CSF flow has been linked to the RF and motile cilia abnormalities resulting in hydrocephalus and scoliosis (Cifuentes et al. 1994; Perez-Figares et al. 2001; Lang et al. 2006; Grimes et al. 2016; Boswell and Ciruna 2017; Cantaut-Belarif et al. 2018). Juvenile scoliosis develops in correlation with destabilization of the RF (Troutwine et al. 2020; Vesque et al. 2019, unpublished). Chll has been suggested as a susceptibility gene of adolescent idiopathic scoliosis (Sharma et al. 2011), although this idea remains short on supporting evidence (Qiu et al. 2014). Our study demonstrates the role of camel in the development of the BVS, formation of the RF, and straightening of the body axis, which has been linked with the proper development of axial structures and, in particular, the RP (Kondrychyn et al. 2013; Korzh 2018). And, it provides experimental evidence to support an idea that Chll could be a candidate gene for idiopathic scoliosis.

In the zebrafish model of scoliosis, there is a failure to straighten the body axis during development (Grimes et al. 2016; Cantaut-Belarif et al. 2018; Troutwine et al. 2020; Vesque et al. 2019, unpublished). During development, the curly tail of zebrafish embryo straightens up at 16-30 hpf and the axial structures (FP, RP, and HC) experience the elastic deformation (Lowery and Sive 2009; Kondrychyn et al. 2013; Shen et al. 2016; Korzh 2018). Upon Camel LOF, embryos fail to straighten and develop extended BVS similar to that in the scoliosis model. This phenotype suggests a role for Camel in the development of the BVS and supports the idea that CHL1 is one of the candidate genes for scoliosis. 


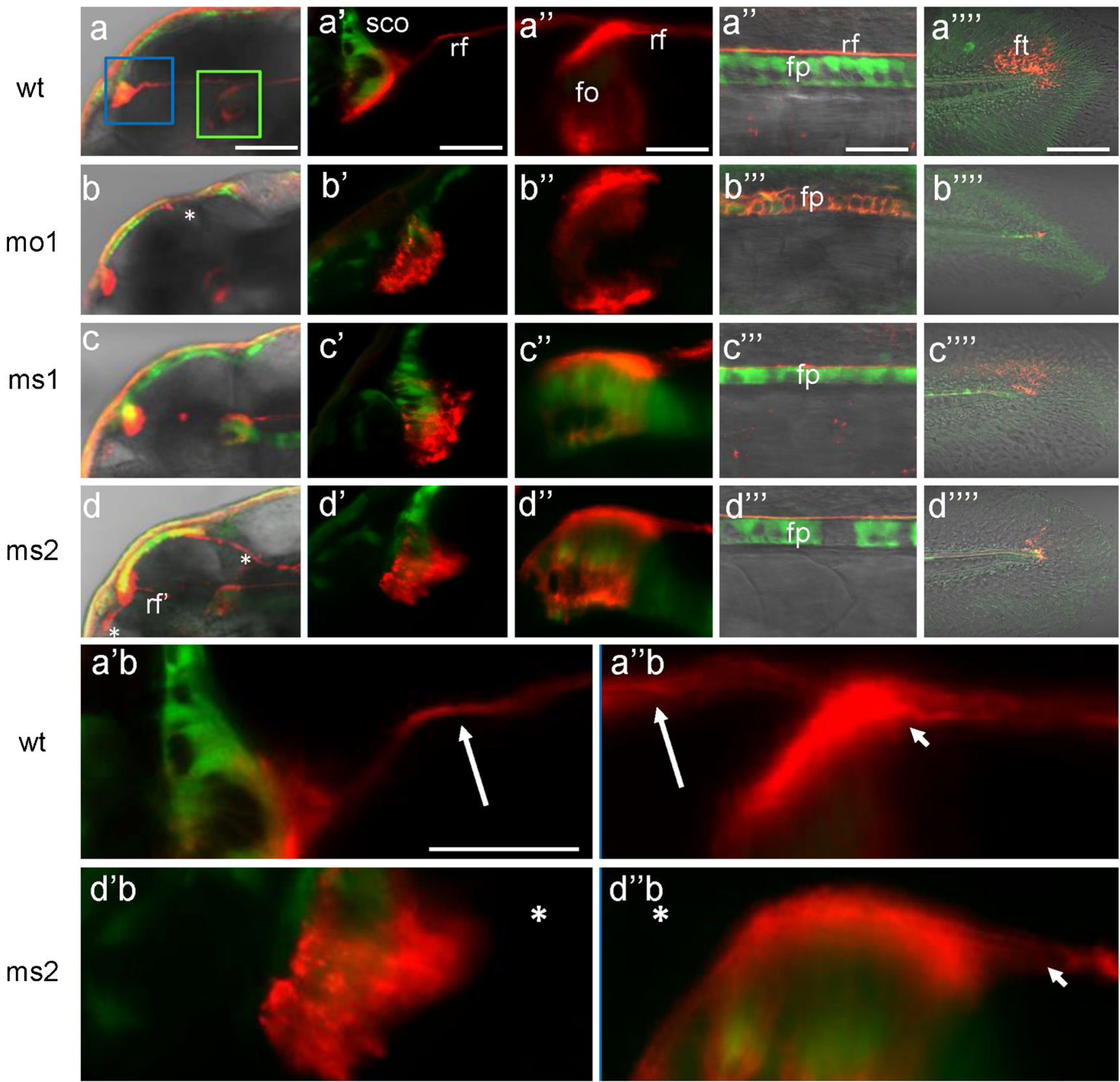

Fig. 10 Pan-Camel and isoform-specific anti-Camel morpholinomediated LOF differentially affects the formation of RF. a Being generated by the SCO (green, GFP, $\operatorname{Tg}(\mathrm{ET} 33$-mi2a) and the RF (detected by anti-AFRU antibody, red) and spanning the BVS. It may obtain additional contributions from FO and FP. It extends through the central canal to the posterior end of the spinal cord to be disassembled at the filum terminale. b MO1 blocks the formation of RF (b') and causes the distortion in the distribution of RF+ material in FO (b") and FP (b"'). c, d In comparison, the effect of isoform-specific morpholinos MS1 and MS2 is less obvious. All confocal images of Tg(ET33-mi2a) transgenic 48-hpf

camel is not expressed in all ependymal cells lining the cavity of the BVS and central canal, but in the CVOs, where ependyma lacks cilia (Krisch et al. 1978; Gross and Weindl 1987). Hence, it is unlikely that motile cilia will be directly affected by Camel LOF. The hydrocephalus and scoliosis in embryos are shown as lateral views with anterior to the left. a Stack of sections. a' Selected sections to illustrate the primarily apical distribution of the RF material in the SCO. a" and $\mathbf{a}$ "' are the same as $\mathbf{c}$ and $\mathbf{d}$ shown for comparing the effect of MO. a'b Blowup of a'. a"b Blowup of a". d'b Blowup of d'. d''b Blowup of d'. Asterisks indicate lack of RF, and arrows and arrowheads indicate RF. Abbreviations: fo, flexural organ; fp, floor plate; ft, filum terminale; rf, Reissner fiber; sco, subcommissural organ. Scale bar $=200 \mu \mathrm{m}$ (upper left-hand side column, a-d), $100 \mu \mathrm{m}$ (four other upper columns marked ' to '"'), and $50 \mu \mathrm{m}$ (blowups)

camel morphants could be due to the abnormal development of CVOs and axial structures, where this gene expresses (Figs. 3 and 4; other data not shown). In particular, SCO, $\mathrm{FO}$, and FP, involved in the formation of RF, seem to be affected in Camel LOF (Fig. 10). The defect of SCO causes 


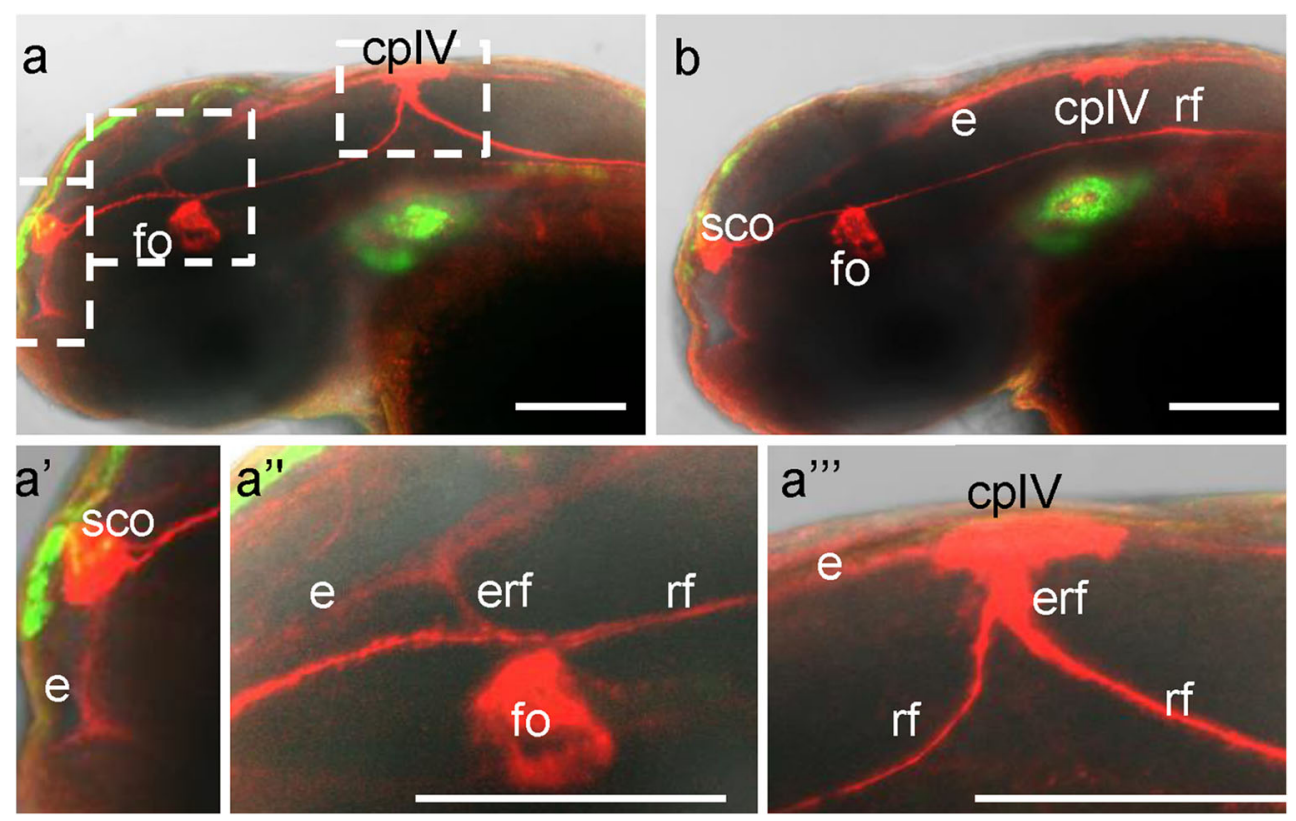

Fig. 11 The overexpression of camel affects the development of the Reissner fiber. Upon camel overexpression, the RF+ material seems to increase in the BVS with its significant redistribution towards the choroid plexus of the fourth ventricle (CPIV) and ependyma (e, anterior and posterior of the SCO). The ectopic sprouts of RF (erf) in the Sylvius aqueduct (sa) formed. In the vIV, the RF changes the ventral trajectory

hydrocephalus (Galarza 2002; Pérez-Fígares et al. 2001; Vio et al. 2000; Louvi and Wassef 2000). Still, a defect of signaling structures such as FP may affect the differentiation of target cells. An excessive RF material could stick either to the signaling or motile cilia, which incapacitates these structures indirectly and influences CSF flow (Fig. 10b). Hence, while cells with motile cilia seem do not express Camel, the indirect effect of Camel on their differentiation and/or function could not be ruled out.

The defects of RF cause hydrocephalus (Cifuentes et al. 1994; Lang et al. 2006; Vio et al. 2008). For example, in the hyh mice deficient in $\alpha$-Snap, the RF is severely affected (Pérez-Fígares et al. 1998; Perez-Figares et al. 2001). This defect results in an ectopic accumulation of the RF material in BVS, which is reminiscent of deficient secretion and distribution of the RF material in camel morphants (Fig. 10). When RF is absent, the embryos fail to straighten their body (FernándezLlebrez et al. 2001; Cantaut-Belarif et al. 2018). Similar to that, the Camel LOF results in the absence of the RF, hydrocephalus, and curly body (Figs. 7b, 8d, and 10b). These defects suggest that Camel acts in the formation of the RF.

Upon Camel GOF, the CPIV takes the role of an ectopic organizing center of RF that changes the RF trajectory (Fig. 11). Here, two possible scenarios could be at play: (i) an ectopic RF material derives from its natural sources (SCO, FO, $\mathrm{FP}$ ) and, when in excess, sticks to $\mathrm{CP}$, or (ii) it is produced by $\mathrm{CP}$ and ependymal cells. The two CVOs in question- the CP and SCO - may derive from the RP (Kiecker 2018; Korzh and (along FP) towards the CPIV in the dorsal position. In the posterior vIV, the trajectory of RF normalizes and leaves the vIV via the central canal. All images are lateral views of $\operatorname{Tg}(\mathrm{ET} 33$-mi2a) transgenic 48-hpf embryos with anterior to the left. a, b Larvae after strong overexpression of Chlla. Boxes in a represent SCO, FO, and CPIV and correspond to a'a"'. Scale bar $=100 \mu \mathrm{m}$

Kondrychyn 2020). These CVOs are similarly affected by ectopic expression of En1 (Louvi and Wassef 2000). It seems the CP and SCO share enough common molecular mechanisms to trigger the ectopic production of RF material in $\mathrm{CP}$. SCO-spondin is not expressed in the $\mathrm{CP}$, unlike that in the $\mathrm{SCO}$, although $\mathrm{CP}$ and SCO do share secretion of TTR (Montecinos et al. 2005), and GFP in the enhancer-trap line ET33-10 (Garcia-Lecea et al. 2017). The CP and SCO are similarly affected by ectopic expression of En1 in the RP that causes early cell death in this structure (Louvi and Wassef 2000).

On the other hand, it has been shown in mammals and birds that during normal development, first, disorganized RF material appears, and second, the RF forms due to the contribution of polymerizing factors (Hoyo-Becerra et al. 2005) with Clu and Lgals1 being the prime candidates for this role (Muñoz et al. 2019). We showed previously that in the developing zebrafish, Clu is expressed in the RP (Jiao et al. 2011; Jeong et al. 2014). The CP and SCO of zebrafish express lgals $2 a$ and lgals $2 b$ genes (Thijssen et al. 2006). Since Camel LOF inhibits the secretion of RF material in SCO and FP (Fig. 10a, b), an ectopic RF material likely derives from its natural sources (SCO, FO, FP) and, when in excess, sticks to the CPIV, which is one of the sources of factors involved in RF polymerization.

Camel as a member of the neural CAM family could be critical for adhesion of cells in the SCO, FO, and FP. The results of experiments in "hanging drops" taken along with observation of changes of the shape of SCO and FP in Camel LOF embryos confirm this notion (Figs. 6 and 10b"). The 

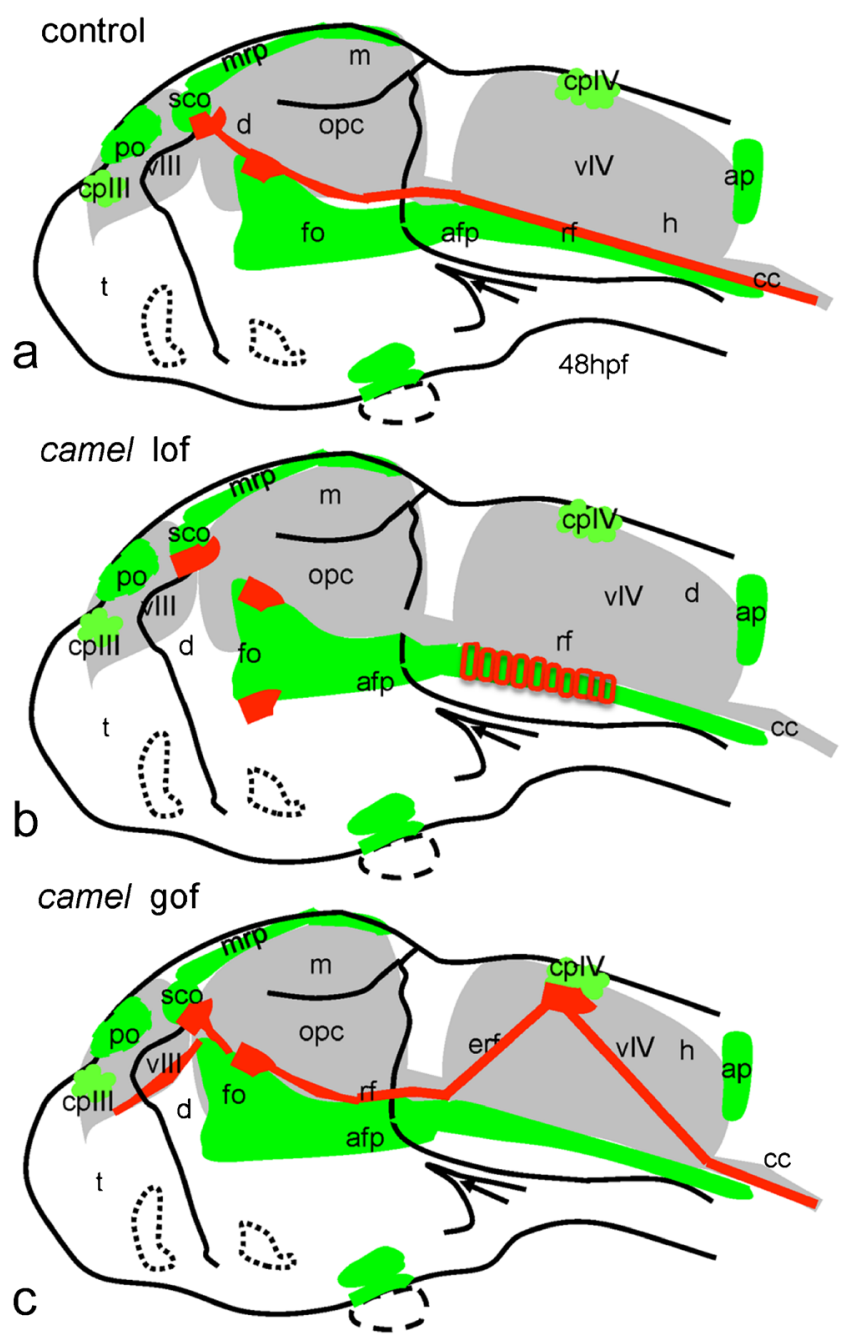

Fig. 12 Schematics show organization of the Reissner fiber in respect of the ventricular system (based on Figs. 9, 10, and 11). a-c 48 hpf. a Controls. b Anti-Camel morpholino-mediated loss-of-function. c Camel mRNA-mediated gain-of-function. Green color, midline structures and some CVOs; red, RF and AFRU+ material. Abbreviations: afp, anterior floor plate; ap, area postrema; cc, central canal; cpIII, choroid plexus of the third ventricle; cpIV, choroid plexus of the fourth ventricle; d, diencephalon; e, epiphysis; erf, ectopic Reissner fiber; h, hindbrain; fo, flexural organ; fp, floor plate; $\mathrm{m}$, midbrain; mrp, midbrain roof plate; opc, optocoele (Sylvius aqueduct); po, pineal organ; rf, Reissner fiber; sco, subcommissural organ; t, telencephalon; vIII, third ventricle; vIV, fourth ventricle

differential activity of its isoforms regulated by differential splicing at the level of one of the fibronectin domains seems to add another level of complexity in the regulation of cell adhesion in the BVS.

It seems that the CVOs are subjects of elastic deformation similar to the RP and FP (Kondrychyn et al. 2013). During development, the SCO transforms from a line of relatively short columnar cells into the iron-shaped pocket of elongated cells. Given that the SCO generates the RF and remains connected to it, perhaps, the CSF flow pulls the RF and attached SCO cells towards posterior, resulting in the morphogenetic change of the SCO. The results of the Camel LOF agree with this suggestion. In the absence of the RF, the morphant SCO remains rather flat (Figs. 9 and 10).

Here, we demonstrated that the Chl1-related CAM Camel plays a role during neural development by regulating cell adhesion in the axial structures of developing zebrafish, RP, FP, and the RP-derived SCO. Camel deficiency results in the failure of the development of RF, hydrocephalus, and scoliosis.

Acknowledgments The authors are thankful to Drs. J. Grondona (Spain), E. Rodriguez, and M. Guerra (Chile) for providing anti-RF antibodies. VK is thankful to Prof. Jacek Kuznicki and his lab members at the IIMCB in Warsaw for the fruitful discussions and criticism.

Authors' contribution Camel cloning was performed by AE and SY; whole-mount in situ hybridization by SY, AE, and VK; mRNA splice variant analysis by SY; hanging drops by SY; the morpholino KD by SY and YMS; and the hydrocephalus rescue by MS; Camel GOF and confocal imaging were performed by SY and manuscript writing and approval by VK.

Funding VK's laboratory in the IMCB, Singapore, was supported by the institutional grant to the IMCB by the Agency for Science, Technology and Research of Singapore. VK in Poland was supported by the Opus grant of the National Science Foundation (NCN), Poland (2016/21/B/ NZ3/00354).

\section{Compliance with ethical standards}

Conflict of interest The authors declare that they have no conflict of interest.

Ethical approval This article does not contain any studies with human participants performed by any of the authors. All experiments with zebrafish were carried according to the regulations of the Institutional Animal Care and Use Committee (Biological Resource Center of Biopolis, Singapore, license no. 120787), which approved this study.

Open Access This article is licensed under a Creative Commons Attribution 4.0 International License, which permits use, sharing, adaptation, distribution and reproduction in any medium or format, as long as you give appropriate credit to the original author(s) and the source, provide a link to the Creative Commons licence, and indicate if changes were made. The images or other third party material in this article are included in the article's Creative Commons licence, unless indicated otherwise in a credit line to the material. If material is not included in the article's Creative Commons licence and your intended use is not permitted by statutory regulation or exceeds the permitted use, you will need to obtain permission directly from the copyright holder. To view a copy of this licence, visit http://creativecommons.org/licenses/by/4.0/.

\section{References}

Alsanie WF, Penna V, Schachner M, Thompson LH, Parish CL (2017) Homophilic binding of the neural cell adhesion molecule CHL1 regulates development of ventral midbrain dopaminergic pathways. Sci Rep 7(1):9368. https://doi.org/10.1038/s41598-017-09599-y 
Angeloni D, Lindor NM, Pack S, Latif F, Wei MH, Lerman MI (1999) CALL gene is haploinsufficient in a 3p- syndrome patient. Am J Med Genet 86:482-485. https://doi.org/10.1002/(sici)10968628(19991029)86:5<482::aid-ajmg15>3.0.co;2-1

Becker CG, Lieberoth BC, Morellini F, Feldner J, Becker T, Schachner M (2004) L1.1 is involved in spinal cord regeneration in adult zebrafish. J Neurosci 24:7837-7842. https://doi.org/10.1523/ JNEUROSCI.2420-04.2004

Ben-Hur T, Rogister B, Murray K, Rougon G, Dubois-Dalcq M (1998) Growth and fate of PSA-NCAM+ precursors of the postnatal brain. J Neurosci 18:5777-5788

Boswell CW, Ciruna B (2017) Understanding idiopathic scoliosis: a new Zebrafish School of Thought. Trends Genet 33:183-196. https://doi. org/10.1016/j.tig.2017.01.001

Braasch I, Gehrke AR, Smith JJ, Kawasaki K, Manousaki T, Pasquier J, Amores A, Desvignes T, Batzel P, Catchen J, Berlin AM, Campbell MS, Barrell D, Martin KJ, Mulley JF, Ravi V, Lee AP, Nakamura T, Chalopin D, Fan S, Wcisel D, Caestro C, Sydes J, FEG B, Sun Y, Hertel J, Beam MJ, Fasold M, Ishiyama M, Johnson J, Kehr S, Lara M, Letaw JH, Litman GW, Litman RT, Mikami M, Ota T, Saha NR, Williams L, Stadler PF, Wang H, Taylor JS, Fontenot Q, Ferrara A, SMJ S, Aken B, Yandell M, Schneider I, Yoder JA, Volff JN, Meyer A, Amemiya CT, Venkatesh B, PWH H, Guiguen Y, Bobe J, Shubin NH, Di Palma F, Alföldi J, Lindblad-Toh K, Postlethwait JH (2016) The spotted gar genome illuminates vertebrate evolution and facilitates human-teleost comparisons. Nat. Genet 48(4):427437. https://doi.org/10.1038/ng.3526

Cantaut-Belarif Y, Sternberg JR, Thouvenin O, Wyart C, Bardet PL (2018) The Reissner fiber in the cerebrospinal fluid controls morphogenesis of the body axis. Curr Biol. 28: 2479-2486.e4. doi: https://doi.org/10.1016/j.cub.2018.05.079

Chesler M, Nicholson C (1985) Organization of the filum terminale in the frog. J Comp Neurol 239:431-444. https://doi.org/10.1002/cne. 902390409

Cifuentes M, Rodríguez S, Pérez J, Grondona JM, Rodríguez EM, Fernández-Llebrez P (1994) Decreased cerebrospinal fluid flow through the central canal of the spinal cord of rats immunologically deprived of Reissner's fibre. Exp Brain Res 98:431-440. https://doi. org/10.1007/BF00233981

Crossin KL, Krushel LA (2000) Cellular signaling by neural cell adhesion molecules of the immunoglobulin superfamily. Dev Dyn 218:260 279. https://doi.org/10.1002/(SICI)1097-0177(200006)218:2<260:: AID-DVDY3>3.0.CO;2-9)

Date P, Ackermann P, Furey C, Fink IB, Jonas S, Khokha MK, Kahle KT, Deniz E (2019) Visualizing flow in an intact CSF network using optical coherence tomography: implications for human congenital hydrocephalus. Sci Rep 9(1):6196. https://doi.org/10.1038/s41598019-42549-4

Dheen T, Sleptsova-Friedrich I, Xu Y, Clark M, Lehrach H, Gong Z, Korzh V (1999) Zebrafish tbx-c functions during formation of midline structures. Development 126:2703-2713

Doherty P, Walsh FS (1996) CAM-FGF receptor interactions: a model for axonal growth. Mol Cell Neurosci 8:99-111. https://doi.org/10. 1006/mene.1996.0049

Fame RM, Chang JT, Hong A, Aponte-Santiago NA, Sive H (2016) Directional cerebrospinal fluid movement between brain ventricles in larval zebrafish. Fluids Barriers CNS 13:11. https://doi.org/10. 1186/s12987-016-0036-Z

Fernández-Llebrez P, Hernández S, Andrades J (2001) Immunocytochemical detection of Reissner's fiber-like glycoproteins in the subcommissural organ and the floor plate of wildtype and cyclops mutant zebrafish larvae. Cell Tissue Res 305(1):115120. https://doi.org/10.1007/s004410100404

Fong SH, Emelyanov A, Teh C, Korzh V (2005) Wnt signalling mediated by $\mathrm{Tb} 2 \mathrm{~b}$ regulates cell migration during formation of the neural plate. Development 132:3587-3596. https://doi.org/10.1242/dev. 01933

Frints SGM, Marynen P, Hartmann D, Fryns JP, Steyaert J, Schachner M, Rolf B, Craessaerts K, Snellinx A, Hollanders K, D’Hooge R, De Deyn PP, Froyen G (2003) CALL interrupted in a patient with nonspecific mental retardation: gene dosage-dependent alteration of murine brain development and behavior. Hum Mol Genet 12(13): 1463-1474. https://doi.org/10.1093/hmg/ddg165

Galarza M (2002) Evidence of the subcommissural organ in humans and its association with hydrocephalus. Neurosurg Rev 25:205-215. https://doi.org/10.1007/s10143-002-0208-y

Gallegos TF, Kamei CN, Rohly M, Drummond IA (2019) Fibroblast growth factor signaling mediates progenitor cell aggregation and nephron regeneration in the adult zebrafish kidney. Dev Biol 454: 44-51. https://doi.org/10.1016/j.ydbio.2019.06.011

García-Lecea M, Gasanov E, Jedrychowska J, Kondrychyn I, Teh C, You MS, Korzh V (2017) Development of circumventricular organs in the mirror of Zebrafish enhancer-trap transgenics. Front Neuroanat 7(11):114. https://doi.org/10.3389/fnana.2017.00114

Gasanov EV, Jędrychowska J, Kuźnicki J, Korzh V (2020) Evolutionary context can clarify teleosts gene names. bioRxiv 2020.02.02.931493; doi: https://doi.org/10.1101/2020.02.02. 931493

Gobron S, Monnerie H, Meiniel R, Creveaux I, Lehmann W, Lamalle D, Dastugue B, Meiniel A (1996) SCO-spondin: a new member of the thrombospondin family secreted by the subcommissural organ is a candidate in the modulation of neuronal aggregation. J Cell Sci 109(Pt 5):1053-1061

Gobron S, Creveaux I, Meiniel R, Didier R, Dastugue B, Meiniel A (1999) SCOspondin is evolutionarily conserved in the central nervous system of the chordate phylum. Neuroscience 88:655-664. https://doi.org/10.1016/s0306-4522(98)00252-8

Grimes DT, Boswell CW, Morante NFC, Henkelman RM, Burdine RD, Ciruna B (2016) Zebrafish models of idiopathic scoliosis link cerebrospinal fluid flow defects to spine curvature. Science 352:13411344. https://doi.org/10.1126/science.aaf6419

Gross PM, Weindl A (1987) Peering through the windows of the brain. J Cereb Blood Flow Metab 7:663-672. https://doi.org/10.1038/jcbfm. 1987.120

Guinazu MF, Richter HG, Rodriguez EM (2002) Bovine floor plate explants secrete SCO-spondin. Cell Tissue Res 308:177-191. https:// doi.org/10.1007/s00441-002-0511-5

Higashijima S, Nose A, Eguchi G, Hotta Y, Okamoto H (1997) Mindin/ F-spondin family: novel ECM proteins expressed in the zebrafish embryonic axis. Dev Biol 192:211-227. https://doi.org/10.1006/ dbio.1997.8760

Hoyo-Becerra C, López-Avalos MD, Alcaide-Gavilán M, GómezRoldán MC, Pérez J, Fernández-Llebrez P, Grondona JM (2005) Reissner's fiber formation depends on developmentally regulated factors extrinsic to the subcommissural organ. Cell Tissue Res 321:429-441. https://doi.org/10.1007/s00441-004-1040-1

Itoh M, Kim C-H, Palardy G, Oda T, Jiang YJ, Maust D, Yeo SY, Lorick K, Wright GJ, Ariza-McNaughton L, Weissman AM, Lewis J, Chandrasekharappa SC, Chitnis AB (2003) Mind bomb is a ubiquitin ligase that is essential for efficient activation of notch signaling by delta. Dev Cell 4:67-82. https://doi.org/10.1016/s1534-5807(02) 00409-4

Jeong Y-M, Jin T-E, Choi J-H, Lee MS, Kim HT, Hwang KS, Park DS, Oh HW, Choi JK, Korzh V, Schachner M, You KH, Kim CH (2014) Induction of clusterin expression by neuronal cell death in zebrafish. J Genet Genomics 41:583-589. https://doi.org/10.1016/j.jgg.2014. 08.007

Jiao S, Dai W, Lu L, Liu Y, Zhou J, Li Y, Korzh V, Duan C (2011) The conserved clusterin gene is expressed in the developing choroid plexus under the regulation of notch but not IGF signaling in 
zebrafish. Endocrinology 152:1860-1871. https://doi.org/10.1210/ en.2010-1183

Jiménez AJ, Tomé M, Páez P, Wagner C, Rodríguez S, FernándezLlebrez P, Rodríguez EM, Pérez-Fígares JM (2001) A programmed ependymal denudation precedes congenital hydrocephalus in the hyh mutant mouse. J Neuropathol Exp Neurol 60:1105-1119. https://doi.org/10.1093/jnen/60.11.1105

Joly JS, Osório J, Alunni A, Auger H, Kano S, Rétaux S (2007) Windows of the brain: towards a developmental biology of circumventricular and other neurohemal organs. Semin Cell Dev Biol 18:512-524. https://doi.org/10.1016/j.semcdb.2007.06.001

Kahle KT, Kulkarni AV, Limbrick DD, Warf BC (2016) Hydrocephalus in children. Lancet 387:788-799. https://doi.org/10.1016/S01406736(15)60694-8

Kiecker C (2018) The origins of the circumventricular organs. J Anat 232:540-553. https://doi.org/10.1111/joa.12771

Kimmel CB, Ballard WW, Kimmel SR, Ullmann B, Schilling TF (1995) Stages of embryonic development of the zebrafish. Dev Dyn 203(3): 253-310. https://doi.org/10.1002/aja.1002030302

Kondrychyn I, Garcia-Lecea M, Emelyanov A, Parinov S, Korzh V (2009) Genome-wide analysis of Tol2 transposon reintegration in zebrafish. BMC Genomics 10:418. https://doi.org/10.1186/14712164-10-418

Kondrychyn I, Teh C, Garcia-Lecea M, Guan Y, Kang A, Korzh V (2011) Zebrafish enhancer TRAP transgenic line database ZETRAP 2.0. Zebrafish 8:181-182. https://doi.org/10.1089/zeb. 2011.0718

Kondrychyn I, Teh C, Sin M, Korzh V (2013) Stretching morphogenesis of the roof plate and formation of the central canal. PLoS One 8:112. https://doi.org/10.1371/journal.pone.0056219

Korzh V, Kondrychyn I (2020) Origin and development of circumventricular organs in living vertebrate. Semin Cell Dev Biol 102:13-20. https://doi.org/10.1016/j.semcdb.2019.10.010

Korzh V (2018) Development of brain ventricular system. Cell Mol Life Sci 75(3):375-383. https://doi.org/10.1007/s00018-017-2605-y

Korzh V, Sleptsova I, Liao J, He J, Gong Z (1998) Expression of zebrafish bHLH genes ngn1 and nrd defines distinct stages of neural differentiation. Dev Dyn 213:92-104. https://doi.org/10.1002/ (SICI)1097-0177(199809)213:1\&1t;92::AIDAJA9\&gt;3.0.CO;2-T

Krisch B, Leonhardt H, Buchheim W (1978) The functional and structural border between the CSF-and blood-milieu in the circumventricular organs (organum vasculosum laminae terminalis, subfornical organ, area postrema) of the rat. Cell Tissue Res 195: 485-497. https://doi.org/10.1007/BF00233891

Kulahin N, Li S, Hinsby A, Kiselyov V, Berezin V, Bock E (2008) Fibronectin type III (FN3) modules of the neuronal cell adhesion molecule L1 interact directly with the fibroblast growth factor (FGF) receptor. Mol Cell Neurosci 37:528-536. https://doi.org/10.1016/j. mon.2007.12.001

Lang B, Song B, Davidson W, MacKenzie A, Smith N, McCaig CD, Harmar AJ, Shen S (2006) Expression of the human PAC1 receptor leads to dose-dependent hydrocephalus-related abnormalities in mice. J Clin Invest 116:1924-1934. https://doi.org/10.1172/ JCI27597

Larison KD, Bremiller R (1990) Early onset of phenotype and cell patterning in the embryonic zebrafish retina. Development 109(3):567576

Latimer AJ, Appel B (2006) Notch signaling regulates midline cell specification and proliferation in zebrafish. Dev Biol 206(298):392-402. https://doi.org/10.1016/j.ydbio.2006.05.039

Lehmann C, Naumann WW (2005) Axon pathfinding and the floor plate factor Reissner's substance in wildtype, cyclops and one-eyed pinhead mutants of Danio rerio. Dev Brain Res 154:1-14. https://doi. org/10.1016/j.devbrainres.2004.09.009

Louvi A, Wassef M (2000) Ectopic engrailed 1 expression in the dorsal midline causes cell death, abnormal differentiation of circumventricular organs and errors in axonal pathfinding. Development 127:4061-4071

Lowery LA, Sive H (2009) Totally tubular: the mystery behind function and origin of the brain ventricular system. BioEssays 31:446-458. https://doi.org/10.1002/bies.200800207

Maness PF, Schachner M (2007) Neural recognition molecules of the immunoglobulin superfamily: signaling transducers of axon guidance and neuronal migration. Nat Neurosci 10(1):19-26. https://doi. org/10.1038/nn1827

Meiniel O, Meiniel R, Lalloué F, Didier R, Jauberteau MO, Meiniel A, Petit D (2008) The lengthening of a giant protein: when, how, and why? J Mol Evol 66:1-10. https://doi.org/10.1007/s00239-0079055-3

Montecinos HA, Richter H, Caprile T, Rodríguez EM (2005) Synthesis of transthyretin by the ependymal cells of the subcommissural organ. Cell Tissue Res 320:487-499. https://doi.org/10.1007/s00441004-0997-0

Muñoz RI, Kähne T, Herrera H, Rodríguez S, Guerra MM, Vío K, Hennig R, Rapp E, Rodríguez E (2019) The subcommissural organ and the Reissner fiber: old friends revisited. Cell Tissue Res 375: 507-529. https://doi.org/10.1007/s00441-018-2917-8

Nicholls GE (1913) The structure and development of Reissner's fibre and subcommissural organ. Part 1. Q J Microsc Sci 58 (part 1):1116

Neumann CJ, Nusslein-Volhard C (2000) Patterning of the zebrafish retina by a wave of sonic hedgehog activity. Science 289:21372139. https://doi.org/10.1126/science.289.5487.2137

Nualart F, Hein S, Yulis CR, Zárraga AM, Araya A, Rodríguez EM (1998) Partial sequencing of Reissner's fiber glycoprotein I (RFGly I). Cell Tissue Res 292:239-250. https://doi.org/10.1007/ s004410051055

Oksche A (1964) Das Subkommissuralorgan des Menschen. Verh Anat Ges 58:373-383

Oksche A (1969) The subcommissural organ. J Neuro Visc Rel Suppl. IX:111-139

Olsson R (1956) The development of Reissner's fibre in the brain of the salmon. Acta Zool (Stockh) 37:235-250

Olsson R (1958) Studies on the subcommissural organ. Acta Zool (Stockh) 39:71-102

Oxtoby E, Jowett T (1993) Cloning of the zebrafish krox-20 gene (krx20 ) and its expression during hindbrain development. Nucleic Acids Res 21:1087-1095. https://doi.org/10.1093/nar/21.5.1087

Parinov S, Kondrichin I, Korzh V, Emelyanov A (2004) Tol2 transposonmediated enhancer trap to identify developmentally regulated zebrafish genes in vivo. Dev Dyn 231:449-459. https://doi.org/10. 1002/dvdy.20157

Pérez-Fígares JM, Jiménez AJ, Pérez-Martín M, Fernández-Llebrez P, Cifuentes M, Riera P, Rodríguez S, Rodríguez EM (1998) Spontaneous congenital hydrocephalus in the mutant mouse hyh. Changes in the ventricular system and the subcommissural organ. J Neuropathol Exp Neurol 57(2):188-202. https://doi.org/10.1097/ 00005072-199802000-00010

Perez-Figares JM, Jimenez AJ, Rodriguez EM (2001) Sucommissural organ, cerebrospinal fluid circulation and hydrocephalus. Microsc Res Tech 52:591-607. https://doi.org/10.1007/s13398-014-0173-7. 2

Poltorak M, Wright R, Hemperly JJ, Torrey EF, Issa F, Wyatt RJ, Freed WJ (1997) Monozygotic twins discordant for schizophrenia are discordant for N-CAM and L1 in CSF. Brain Res 751(1):152-154. https://doi.org/10.1016/s0006-8993(97)00023-1

Pradel G, Schmidt R, Schachner M (2000) Involvement of L1.1 in memory consolidation after active avoidance conditioning in zebrafish. $\mathrm{J}$ Neurobiol 43:389-403

Qiu XS, Lv F, Zhu ZZ, Qian BP, Wang B, Yu Y, Qiu Y (2014) Lack of association between the CHL1 gene and adolescent idiopathic scoliosis susceptibility in Han Chinese: a case-control study. BMC 
Musculoskelet Disord 15:38. https://doi.org/10.1186/1471-247415-38

Redies C (2000) Cadherins in the central nervous system. Prog Neurobiol 61(6):611-648. https://doi.org/10.1016/s0301-0082(99)00070-2

Richter H, Muñoz RI, Millan CS, Guiñazu MF, Yulis CR, Rodríguez EM (2001) The floor plate cells from bovine express the mRNA encoding for SCO-spondin and its translation products. Brain Res Mol Brain Res 93:137-147. https://doi.org/10.1016/S0169328X(01)00181-4

Rodríguez EM, Oksche A, Hein S, Rodríguez S, Yulis R (1984) Comparative immunocytochemical study of the subcommissural organ. Cell Tissue Res 237:427-441. https://doi.org/10.1007/ BF00228427

Rodríguez EM, Herrera H, Peruzzo B, Rodríguez S, Hein S, Oksche A (1986) Light- and electron microscopic immunocytochemistry and lectin histochemistry of the subcommissural organ: evidence for processing of the secretory material. Cell Tissue Res 243:545-559. https://doi.org/10.1007/BF00218061

Rodríguez S, Rodríguez PA, Banse C, Rodríguez EM, Oksche A (1987a) Reissner's fiber, massa caudalis and ampulla caudalis in the spinal cord of lamprey larvae (Geotria australis). Cell Tissue Res 247:359 366

Rodríguez EM, Oksche A, Rodríguez S, Hein S, Peruzzo B, Schoebitz K, Herrera H (1987b) The subcommissural organ and Reissner's fiber. In: Gross PM (ed) Circumventricular organs and body fluids, vol. II. CRC, Boca Raton, pp 3-41

Rodríguez EM, Oksche A, Hein S, Yulis CR (1992) Cell biology of the subcommissural organ. Int Rev Cytol 135:39-121. https://doi.org/ 10.1016/s0074-7696(08)62038-0

Rodriguez EM, Jara P, Richter H, Montecinos H, Flandes B, Wiegand R, Oksche A (1993) Evidence for the release of CSF-soluble secretory material from the subcommissural organ, with particular reference to the situation in the human. In The subcommissural organ an ependymal brain gland Edited by: Oksche A, Rodriguez EM, Fernandez-Llebrez P. New York: Springer; 121-131

Rodríguez EM, del Brío León MA, Riera P, Menendez J, Schoebitz K (1996) The floor plate of the hindbrain is a highly specialized gland. Immunocytochemical and ultrastructural characteristics. Brain Res Dev Brain Res 97:153-168

Rodríguez EM, Rodríguez S, Hein S (1998) The subcommissural organ. Microsc Res Tech 41:98-123

Rodríguez EM, Oksche A, Montecinos H (2001) Human subcommissural organ, with particular emphasis on its secretory activity during the fetal life. Microsc Res Tech 52:573-590. https://doi.org/10.1002/ 1097-0029(20010301)52:5<573::AID-JEMT1042>3.0.CO;2-6

Roelink H, Augsburger A, Heemskerk J, Korzh V, Norlin S, Ruiz i Altaba A, Tanabe Y, Placzek M, Edlund T, Jessell T, Dodd J (1994) Floor plate and motor neuron induction by vhh-1, a vertebrate homolog of hedgehog expressed by the notochord. Cell 76: 761-775. https://doi.org/10.1016/0092-8674(94)90514-2

Rolf B, Kutsche M, Bartsch U (2001) Severe hydrocephalus in L1deficient mice. Brain Res 891(1-2):247-252. https://doi.org/10. 1016/s0006-8993(00)03219-4

Sampath K, Rubinstein AL, Cheng AMS, Liang J, Fekany K, SolnicaKrezel S, Korzh V, Halpern M, Wright CVE (1998) Induction of the zebrafish ventral brain and floorplate requires cyclops/nodal signalling. Nature 395(6698):185-189. https://doi.org/10.1038/26020

Schlatter MC, Buhusi M, Wright AG, Maness PF (2008) CHL1 promotes Sema3A-induced growth cone collapse and neurite elaboration through a motif required for recruitment of ERM proteins to the plasma membrane. J Neurochem 104:731-744. https://doi.org/10. 1111/j.1471-4159.2007.05013.x

Senchenko VN, Krasnov GS, Dmitriev AA, Kudryavtseva AV, Anedchenko EA, Braga EA, Pronina IV, Kondratieva TT, Ivanov SV, Zabarovsky ER, Lerman MI (2011) Differential expression of
CHL1 gene during development of major human cancers. PLoS One 6(3):e15612. https://doi.org/10.1371/journal.pone.0015612

Sharma S, Gao X, Londono D, Devroy SE, Mauldin KN, Frankel JT, Brandon JM, Zhang D, Li QZ, Dobbs MB, Gurnett CA, Grant SF, Hakonarson H, Dormans JP, Herring JA, Gordon D, Wise CA (2011) Genome-wide association studies of adolescent idiopathic scoliosis suggest candidate susceptibility genes. Hum Mol Genet 20(7):1456-1466. https://doi.org/10.1093/hmg/ddq571

Shen H, Bocksteins E, Kondrychyn I, Snyders D, Korzh V (2016) Functional antagonism of voltage-gated $\mathrm{K}^{+}$channel $\alpha$-subunits in the developing brain ventricular system. Development 143:42494260. https://doi.org/10.1242/dev.140467

Steinberg MS, Takeichi M (1994) Experimental specification of cell sorting, tissue spreading, and specific spatial patterning by quantitative differences in cadherin expression. Proc Natl Acad Sci U S A 91:206-209. https://doi.org/10.1073/pnas.91.1.206

Sterba G (1969) Morphologie und Funktion des Subcommissuralorgans. In: Sterba G (ed) Zirkumventriculare Organe und Liquor. G Fischer, Jena, pp 17-27

Sternberg JR, Prendergast AE, Brosse L, Cantaut-Belarif Y, Thouvenin O, Orts-Del'Immagine A, Castillo L, Djenoune L, Kurisu S, JR MD, Bardet PL, Boccara C, Okamoto H, Delmas P, Wyart C (2018) $\mathrm{Pkd} 211$ is required for mechanoception in cerebrospinal fluidcontacting neurons and maintenance of spine curvature. Nat Commun 9:3804. https://doi.org/10.1038/s41467-018-06225-x

Thijssen VLJL, Postel R, Brandwijk RJMGE, Dings RP, Nesmelova I, Satijn S, Verhofstad N, Nakabeppu Y, Baum LG, Bakkers J, Mayo KH, Poirier F, Griffioen AW (2006) Galectin-1 is essential in tumor angiogenesis and is a target for antiangiogenesis therapy. Proc Natl Acad Sci U S A 103:15975-15980. https://doi.org/10.1073/pnas. 0603883103

Tongiorgi E, Bernhardt RR, Schachner M (1995) Zebrafish neurons express two L1-related molecules during early axonogenesis. J Neurosci Res 42:547-561. https://doi.org/10.1002/jnr.490420413

Troutwine B, Gontarz P, Minowa R, Monstad-Rios A, Konjikusic M, Sepich D, Kwon RY, Solnica-Krezel S, Gray RS (2020) The Reissner fiber is highly dynamic in vivo and controls morphogenesis of the spine. Curr Biol. May 3. pii: S0960-9822(20)30495-4. doi: https://doi.org/10.1016/j.cub.2020.04.015

Tsuneki K (1986) A survey of occurrence of about seventeen circumventricular organs in brains of various vertebrates with special reference to lower groups. J Hirnforsch 27:441-470

Vio K, Rodríguez S, Navarrete EH, Pérez-Fígares JM, Jiménez AJ, Rodríguez EM (2000) Hydrocephalus induced by immunological blockage of the subcommissural organ-Reissner's fiber (RF) complex by maternal transfer of anti-RF antibodies. Exp Brain Res 135: 41-52. https://doi.org/10.1007/s002210000474

Vio K, Rodríguez S, Yulis CR, Oliver C, Rodríguez EM (2008) The subcommissural organ of the rat secretes Reissner's fiber glycoproteins and CSF-soluble proteins reaching the internal and external CSF compartments. Cerebrospinal Fluid Res 5:3. https://doi.org/ 10.1186/1743-8454-5-3

Vesque C, Anselme I, Pezeron G, Cantaut-Belarif Y, Eschstruth A, Djebar M, Santos DL, Le Ribeuz H, Jenett A, Khoury H, Véziers J, Parmentier C, Schneider-Maunoury S (2019) Loss of the Reissner fiber and increased URP neuropeptide signaling underlie scoliosis in a zebrafish ciliopathy mutant. bioRxiv 2019.12.19.882258; doi: https://doi.org/10.1101/2019.12.19.882258

Wagner C, Batiz LF, Rodríguez S, Jiménez AJ, Páez P, Tomé M, PérezFígares JM, Rodríguez EM (2003) Cellular mechanisms involved in the stenosis and obliteration of the cerebral aqueduct of hyh mutant mice developing congenital hydrocephalus. J Neuropathol Exp Neurol 62:1019-1040. https://doi.org/10.1093/jnen/62.10.1019

Wang X, Emelyanov A, Korzh V, Gong Z (2003) Zebrafish atonal homologue zath3 is expressed during neurogenesis in embryonic 
development. Dev Dyn 227(4):587-592. https://doi.org/10.1002/ dvdy. 10331

Wong EV, Kenwrick S, Willems P, Lemmon V (1995) Mutations in the cell adhesion molecule L1 cause mental retardation. Trends Neurosci 18(4):168-172. https://doi.org/10.1016/0166-2236(95) 93896-6

Yulis CR, Mota MD, Andrades JA, Rodríguez S, Peruzzo B, Mancera JM, Ramirez P, Garrido M, Pérez-Fígarez JM, Fernández-Llebrez P, Rodríguez EM (1998) Floor plate and the subcommissural organ are the source of secretory compounds of related nature: comparative immunocytochemical study. J Comp Neurol 392:19-34. https://doi. org/10.1002/(sici)1096-9861(19980302)392:1<19::aid-cne2>3.0. $\mathrm{co} ; 2$-s

Zhang J, Williams MA, Rigamonti D (2006) Genetics of human hydrocephalus. J Neural 253:1255-1266. https://doi.org/10.1007/s00415006-0245-5

Publisher's note Springer Nature remains neutral with regard to jurisdictional claims in published maps and institutional affiliations. 